\title{
Spatial and Temporal Variation in PBL Height over the Korean Peninsula in the KMA Operational Regional Model
}

\author{
Seung-Jae Lee, ${ }^{1}$ Juwon Lee, ${ }^{2}$ Steven J. Greybush, ${ }^{3}$ Minseok Kang, ${ }^{1}$ and Joon Kim ${ }^{1}$ \\ ${ }^{1}$ National Center for Agro-Meteorology, Seoul National University, 1 Gwanak-ro, Gwanak-gu, Seoul 151-744, Republic of Korea \\ ${ }^{2}$ Forecast Research Laboratory, National Institute of Meteorological Research, 45 Gisangcheong-gil, Dongjak-gu, \\ Seoul 156-720, Republic of Korea \\ ${ }^{3}$ Department of Atmospheric and Oceanic Science, University of Maryland, College Park, MD 20742, USA
}

Correspondence should be addressed to Seung-Jae Lee; email.seungjae.lee@gmail.com

Received 27 May 2013; Accepted 27 August 2013

Academic Editor: Hann-Ming Henry Juang

Copyright (C) 2013 Seung-Jae Lee et al. This is an open access article distributed under the Creative Commons Attribution License, which permits unrestricted use, distribution, and reproduction in any medium, provided the original work is properly cited.

\begin{abstract}
Spatial and temporal variations in planetary boundary layer height (PBLH) over the Korean Peninsula and its surrounding oceans are investigated using a regional grid model operated at the Korea Meteorological Administration (KMA). Special attention is placed on daily maximum mixing height for evaluation against two radiosonde observation datasets. In order to construct a new high-resolution PBLH database with 3-hour time and $10 \mathrm{~km}$ spatial resolution, short-term integrations with the regional model are carried out for a one-year period from June 2010 to May 2011. The resulting dataset is then utilized to explore the seasonal patterns of horizontal PBLH distribution over the peninsula for one year. Frequency distributions as well as monthly and diurnal variations of PBLH at two selected locations are examined. This study reveals specific spatiotemporal structure of boundary layer depth over the Korean Peninsula for the first time at a relatively high-resolution scale. The results are expected to provide insights into the direction for operational tuning and future development in the model boundary layer schemes at KMA.
\end{abstract}

\section{Introduction}

The diurnally evolving structure of the planetary boundary layer (PBL) for a typical synoptic high-pressure system is described by Stull [1]. The depth of the PBL provides important information for numerical weather prediction (NWP) and atmospheric dispersion models. It has been used as a key parameter in the trigger function for convection in cumulus parameterization schemes in many NWP models (e.g., [2, $3]$ ). Accurate prediction of PBL's vertical extent is crucial in determining whether harmful gases (e.g., those erupted from a volcano) would reach the ground or not [4]. It affects nearsurface atmospheric pollutant concentrations (e.g., [5]), lowlevel moisture availability, and updraft conditions prior to thundershowers (e.g., [6]). In particular, daytime mixed-layer (ML) height has been regarded as the location of a capping temperature inversion atop the convective boundary layer. Raupach et al. [7] and Denmead et al. [8] formularized the relationship between carbon dioxide concentration and ML depth through entrainment processes.

To identify the ML top, there have been several methods for which radiosondes, wind profilers, and ceilometer/light detection and ranging (LIDAR) were utilized (e.g., [9-14]). These kinds of techniques to extract PBLH information have been also applied over the Korean Peninsula to surface flux [15-17], radiosonde [18, 19], LIDAR [20], and wind profiler [21] data. Most of the researchers analyzed characteristics of PBLH at one location over the peninsula and obtained several important results. For example, about $60 \%$ of daytime maximum mixing depths estimated at Korean radiosonde sites have been found to vary in a range of 1000-2000 m altitude with higher (lower) values in spring and fall (summer and winter) [18]. Low values in the summertime are associated with the East Asia monsoon starting in June, and wintertime low values are related to the cold air masses of the Siberian high [22]. More recently, Lee et al. [19] developed an empirical 


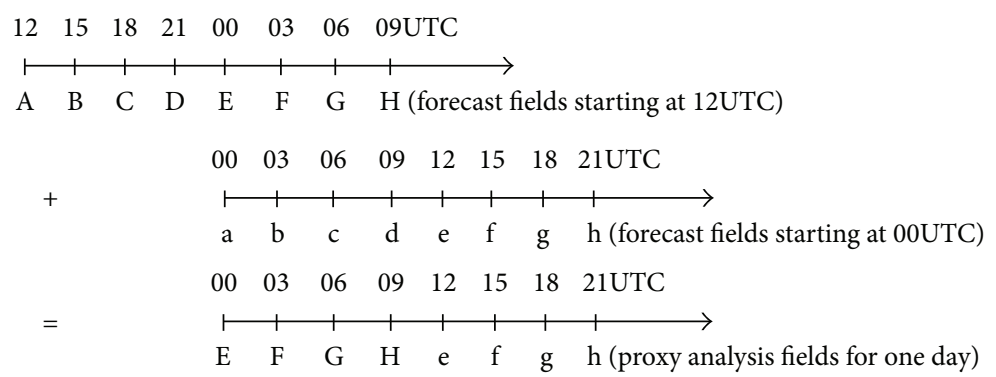

FIGURE 1: Construction of proxy analysis fields of PBLH for one day using short-term model forecast fields. The $00-09 \mathrm{~h}$ forecasts are not used to avoid the model spin-up effect.

algorithm for automated determination of mixing height from mid-day (06UTC or 15LST) radiosonde temperature, relative humidity, and water-vapor mixing ratio profiles.

However, all these studies until now have used observations and estimations of mixing depths at local stations, and thereby the spatial distribution of PBL height and its temporal variation was not well known over the Korean Peninsula. The central goal of this paper is to use an operational regional grid model to obtain a typical PBLH fields over the Korean Peninsula with the least computational cost. A quantitative analysis is also performed for the frequency, horizontal distribution, and monthly and seasonal variation in PBL height over the Korean Peninsula and its surrounding ocean for the first time. Data and methods are presented in Section 2, model evaluation is described in Section 3, and the spatial distribution and temporal variation are shown in Sections 4 and 5, respectively. Summary and concluding remarks are given in Section 6.

\section{Data and Methodology}

2.1. Model PBL Height Data. This study follows Berbery and Collini [23] premise stating that "lacking regional analyses, short-term forecasts with a regional model will serve to add information in regions and times that otherwise would not be available." Based on this idea, we use the KWRF Model, a regional grid model operated at Korea Meteorological Administration (KMA), to fill in regions with no PBLH information. The KWRF initially started from the Weather Research and Forecasting (WRF) system [24]. The KMA implemented its $10 \mathrm{~km}$ resolution version in May 2007 and has continuously modified it for data assimilation, physical parameterization, higher resolution, and other diverse applications [25]. The current version of KWRF is initialized by the global analyses from the KMA UM model (N320/L50) and its boundary condition is updated every $6 \mathrm{~h}$. Horizontal resolution is $10 \mathrm{~km}$ with 40 vertical layers extending from the surface to $10 \mathrm{hPa}$, and a $60 \mathrm{~s}$ time step is used. The inflow/outflow-dependent relaxation method is used for the lateral boundary condition, the radiation method for the top boundary condition, and the daily NOAA SST data for the marine boundary condition. The model physics configuration is composed of the Dudhia shortwave radiation scheme [26], the RRTM longwave radiation scheme [27], the WRF Single Moment 6-class microphysics [28], the New Kain-Fritsch scheme [29], the YSU boundary layer scheme [30], the Monin-Obukhov- Janjić surface layer scheme [3133], and the Noah land surface model [34]. WRF model behavior for East Asia is reported in Lee et al. [35], Choi et al. [36], and Jung et al. [37].

In general, PBL height is not a primary atmospheric variable such as temperature, humidity, and wind, and an objective data analysis scheme does not assimilate it into a numerical model. This is one main reason why the KMA data assimilation and prediction systems do not include the PBL height as an analysis variable. This significantly hinders us from knowing specifically the spatiotemporal structure of PBL height over the Korean Peninsula. Therefore, a strategy is needed in order to construct a basic dataset for the PBL height as accurately as possible. To this end, this study uses short-period integrations of the KWRF. Basically, the dataset consists of a series of $24 \mathrm{~h}$ forecasts at $3 \mathrm{~h}$ intervals starting at 00UTC and 12UTC for each day. Then, a "proxy" analysis field of PBLH can be established by connecting the two $12-21 \mathrm{~h}$ forecasts, starting at 00UTC and 12UTC, respectively (see Figure 1). The $00-09 \mathrm{~h}$ forecasts are not used to avoid the model spin-up effect.

The nonlocal YSU boundary layer scheme uses prescribed eddy diffusivity profiles and permits countergradient terms in the situation of convective boundary mixing. Also, as an upgraded version of the MRF PBL scheme [2, 38], it considers an explicit representation of entrainment at the top of the boundary layer. Stability functions for momentum and heat are determined according to atmospheric stability that has four regimes based on the critical Bulk-Richardson number $\left(\mathrm{Rib}_{\mathrm{cr}}\right)$ : free convection $\left(\mathrm{Rib}_{\mathrm{cr}}<0\right)$, forced convection $\left(\mathrm{Rib}_{\mathrm{cr}}=0\right)$, damped mechanical turbulence $\left(0<\mathrm{Rib}_{\mathrm{cr}}<\right.$ $0.2)$, and stable atmosphere $\left(\operatorname{Rib}_{\mathrm{cr}}>=0.2\right)$. In the scheme, PBL height is diagnosed by

$$
h=\frac{\operatorname{Rib}_{\mathrm{cr}} \theta_{\mathrm{va}}|U(h)|^{2}}{\left[g\left(\theta_{v}(h)-\theta_{s}\right)\right]},
$$

where is $g$ acceleration due to gravity, $\theta_{s}$ and $\theta_{\text {va }}$ are virtual potential temperatures near the model surface and at the lowest sigma level, respectively, $\theta_{v}(h)$ is the virtual potential temperature, and $U(h)$ is the horizontal wind speed at height $h$ of the PBL. In the KWRF model, boundary layer depths at every time steps are always defined through (1). 


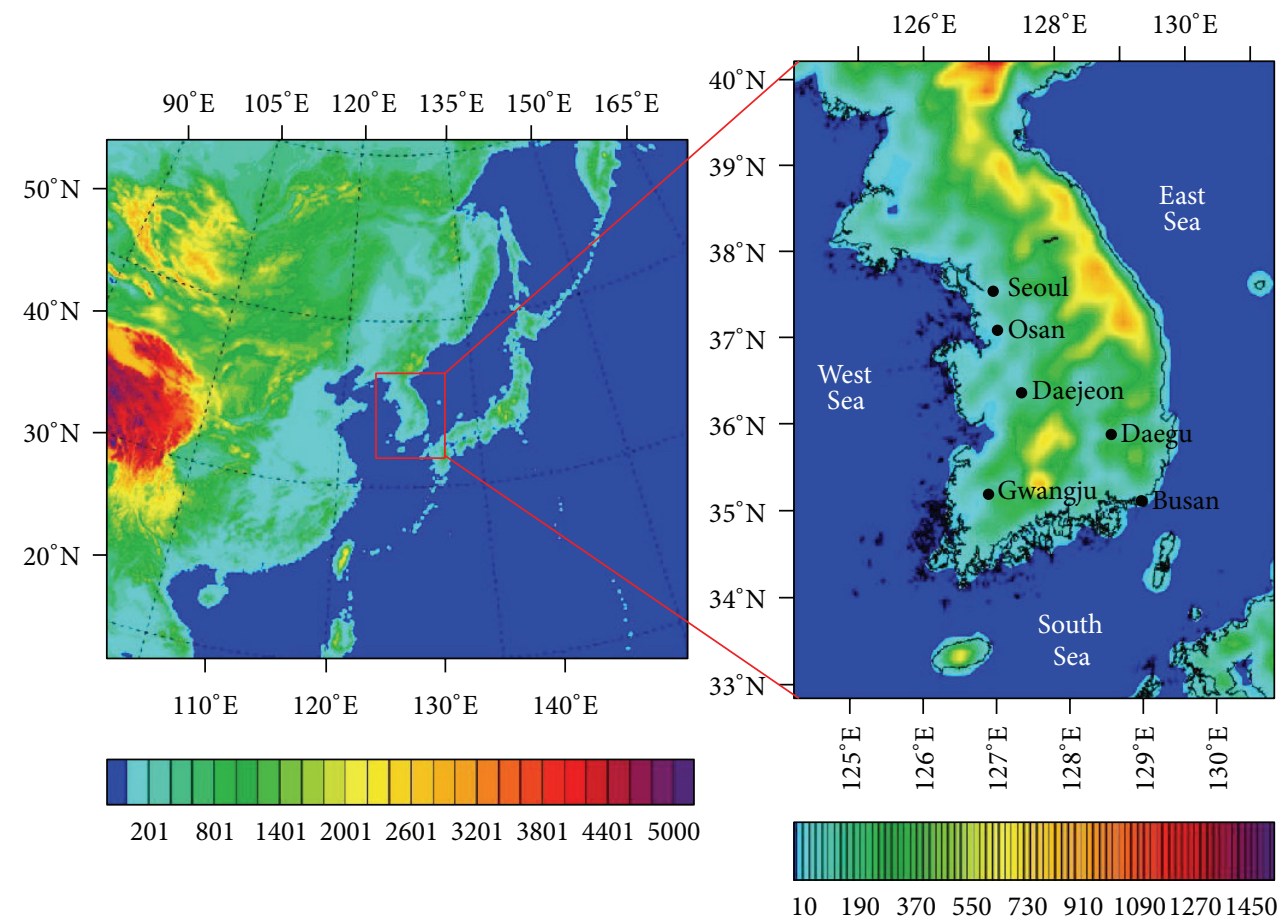

FIGURE 2: Topography used in the KWRF. Geographic locations of representative large cities are shown together with two operational radiosonde sites, Osan and Gwangju. The West Sea, the East Sea (also known as Sea of Japan), and the South Sea are located west, east, and south of the Korean Peninsula. Contour intervals are indicated at the bottom.

Figure 2 shows the model domain and its topographic features. The model topography reproduces the mountain range and the sharp slopes along the east coast of the Korean Peninsula. Seoul, Daejeon, Daegu, Gwangju, and Busan are the largest five cities in the Republic of Korea. A high mountain among Daejeon, Daegu, and Gwangju is known as "Jiri Mountain." Between the mountains, low-altitude regions with terrain heights of no more than $100 \mathrm{~m}$ are spread out toward the west and south seacoasts.

2.2. Observed Data. The KWRF-produced PBLH can be evaluated using remote-sensing equipment such as radiosonde and wind profiler. In this study, two types of radiosonde datasets at Osan site (See Figure 2) are employed for the model evaluation because the data are available for a longtime period (since the 1980s) over Republic of Korea. The first dataset, produced by Choi and Baek [18], is composed of average daily maximum mixing height (DMMH) data for 10 years (1983-1992). Their DMMH data were calculated using a parcel method used by Holzworth [9], where the DMMH is determined as a height where a dry adiabatic line passing through the day's maximum $2 \mathrm{~m}$ temperature intersects a morning (00UTC or 09LST) temperature profile. This 10-year average DMMH data (hereafter, CB98) play an important role as climatological boundary-layer depth data over Republic of Korea.

The second dataset is also composed of DMMH data, but it was created by more direct method to use only midday environmental profiles of virtual potential temperature, mixing ratio and relative humidity measured at 06UTC (15LST). The mid-day (15LST) radiosonde balloon launches have been conducted and archived since 2001 and were used in this study for creating a one-year dataset (June 2010 to May 2011) of DMMH. Hereafter, this DMMH dataset is called RAOB and Lee et al. [19] describe it in more depth.

\section{Comparison of Observed and Modeled PBLH at Osan}

3.1. Osan Radiosonde Observations. While 00UTC and 12UTC profiles of thermodynamic variables over the Korean Peninsula are archived and their spatial and temporal variation are well known, the characteristics of 06UTC (15LST) profiles (a new dataset) have not yet been reported. Since the 06UTC profiles are heavily used for model evaluation, this subsection provides readers with the basic information on the full-range and seasonal variability of the profiles. For this, we visualize them in a spaghetti plot that is useful to trace the individual patterns of vertical profiles at Osan and easily check their daily behavior by season. Figure 3 shows a spaghetti plot of the radiosonde temperature profiles at the Osan site in each of the four seasons. The thin lines correspond to daily 06UTC soundings, and the thick black line is the seasonal mean profile. Seasonal mean of all temperature data (over all dates and levels) ranged from $-9.5^{\circ} \mathrm{C}$ (winter) to $14.6^{\circ} \mathrm{C}$ (summer). It is noticeable that 


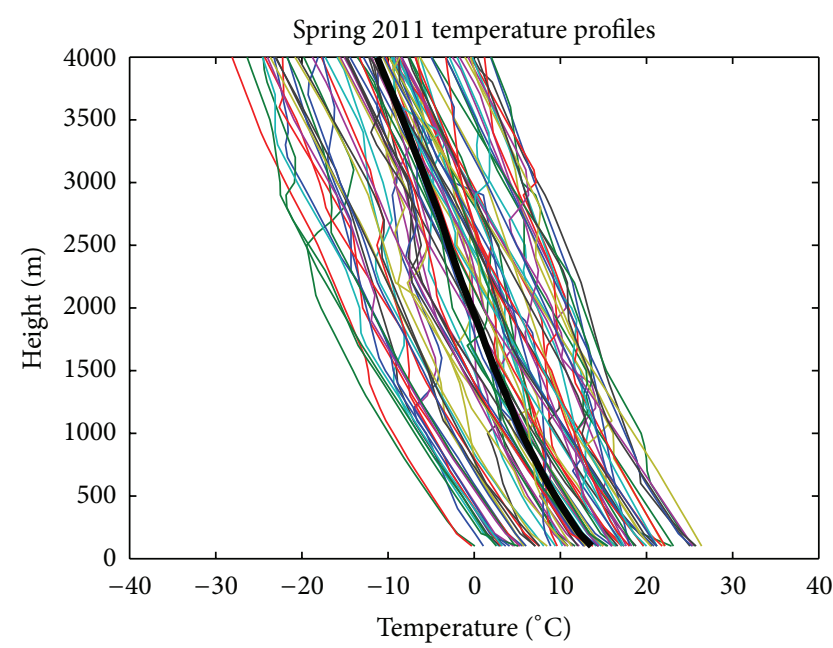

(a)

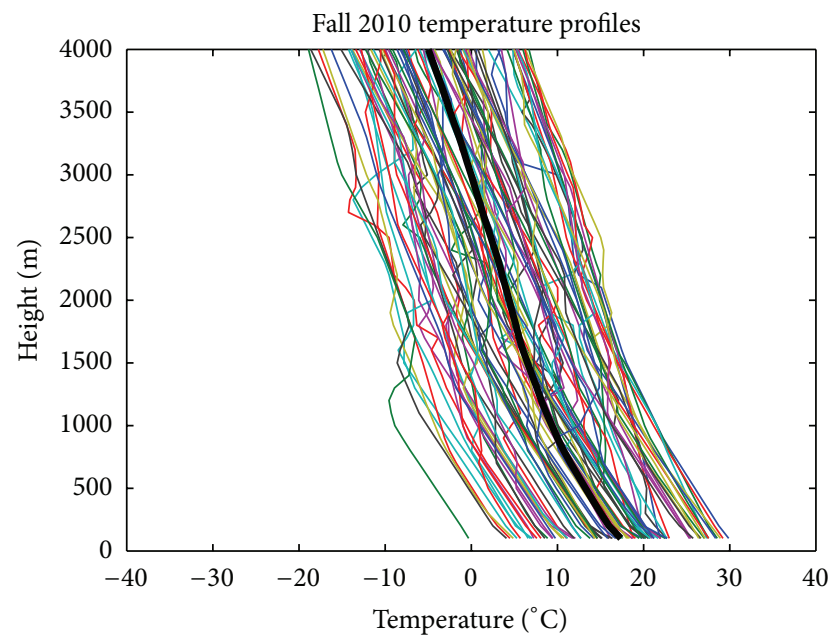

(c)

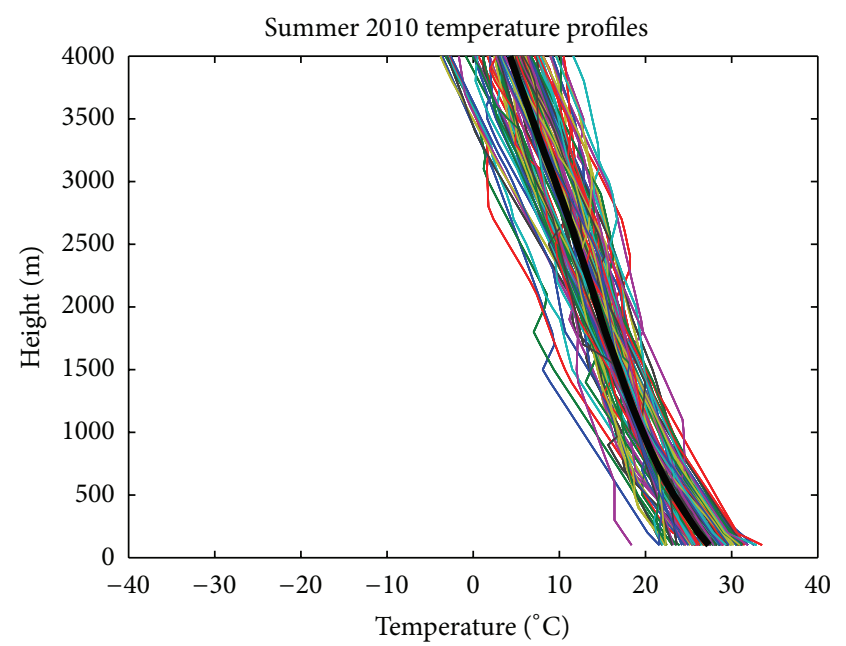

(b)

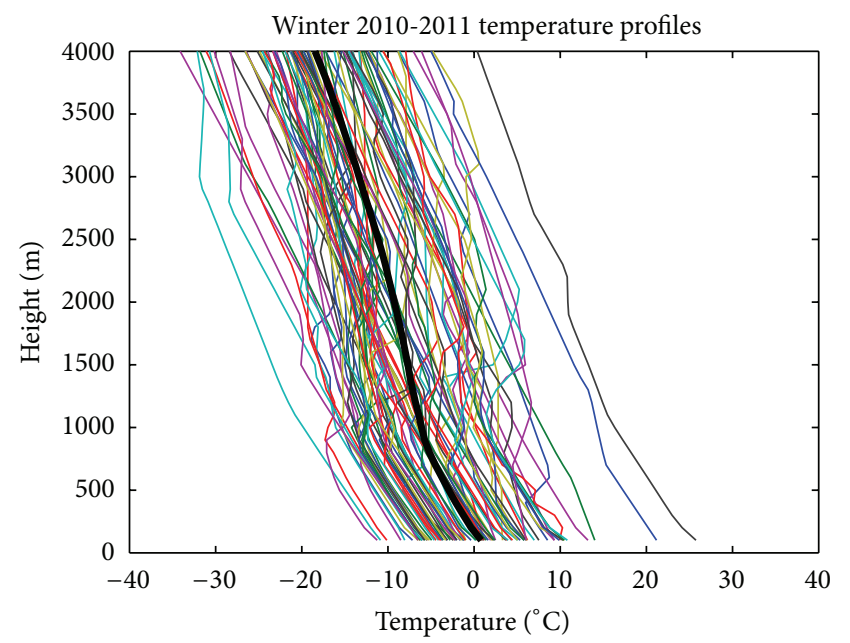

(d)

FIGURE 3: Spaghetti plots for vertical temperature profiles (colored lines) and their mean (thick black line) from 06UTC (15LST) radiosonde observations at Osan in four seasons during the period June 2010-May 2011. Spring 2011 (a), summer 2010 (b), fall 2010 (c), and winter 2011 (d) had 92, 92, 88 (3 missing data), and 90 profiles, respectively.

daily differences in temperature profiles are relatively small in summer with standard deviation of $6.9^{\circ} \mathrm{C}$, compared to $10.1^{\circ} \mathrm{C}$ in spring.

Empirical orthogonal function (EOF) analysis, also known as principal component analysis (PCA), can illuminate the patterns that explain the most variability within a dataset. It is important to be cognizant of these vertical structures in the dataset that may be masked by examining a single metric, such as DMMH, in isolation. The EOF expansion was truncated to 4 , because these vectors together explain $98 \%$ of the variance of the dataset; further details on the methodology for this section are described in the appendix. Figure 4 shows the EOF pattern vectors for the temperature in each season. The first pattern vector in all four seasons slowly increases its magnitude with height and has uniform sign. This represents a shift (warmer or cooler) from the profile mean, which is more pronounced in the upper atmosphere than lower atmosphere. It is noteworthy that the first eigenvector explains considerably less of the variance during summertime (79\% compared to 94,95 , and 91\%), as shown in Figure 3 where the summer season exhibits the smallest spread. This indicates that summertime profiles may exhibit more complex and small scale variations in the vertical. The second eigenvector is nearly monotonically increasing (decreasing) from the surface to the upper atmosphere and represents changes in lapse rate (and hence stability) in the profiles. The third pattern has its maximum at around $1500 \mathrm{~m}$, with a sharply opposite sign near the surface, and could be indicative of a temperature inversion at that level. The fourth pattern has two peaks and can explain finer scale vertical structure in the data. Many of the eigenvectors change sign or slope at around $1000 \mathrm{~m}$, indicating that this level is critical in separating two vertical regimes (i.e., PBL and free atmosphere) in temperature profile shape. 


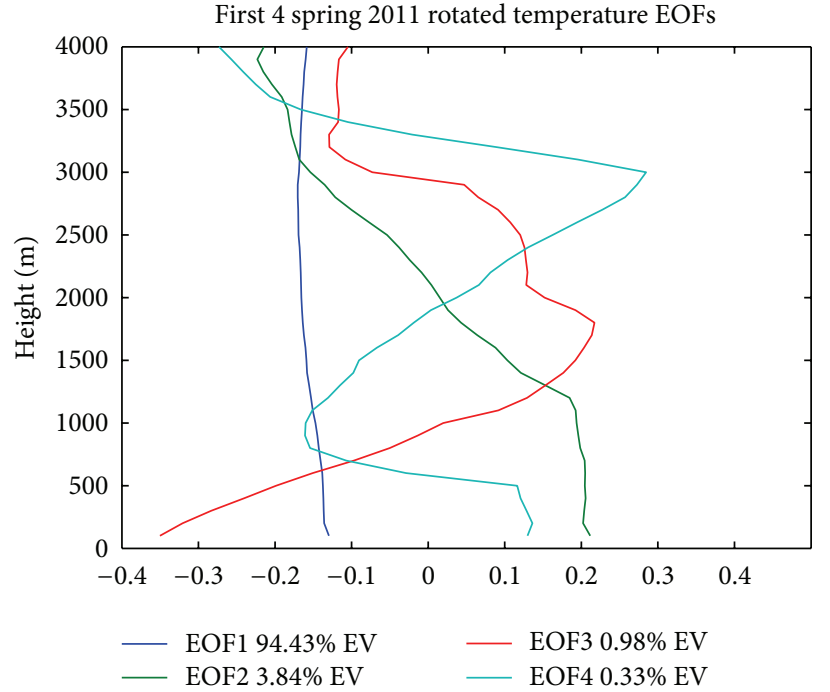

(a)

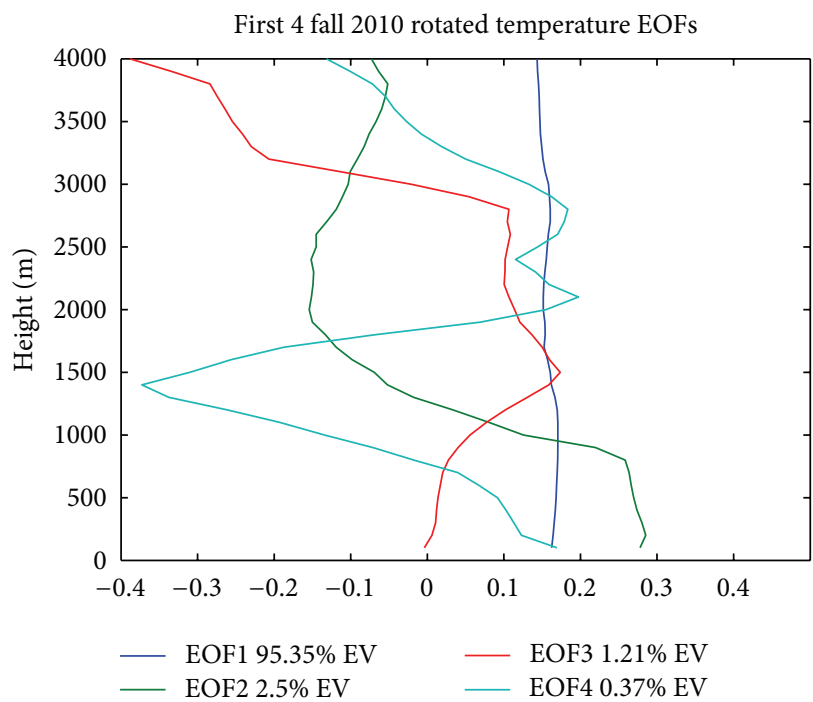

(c)

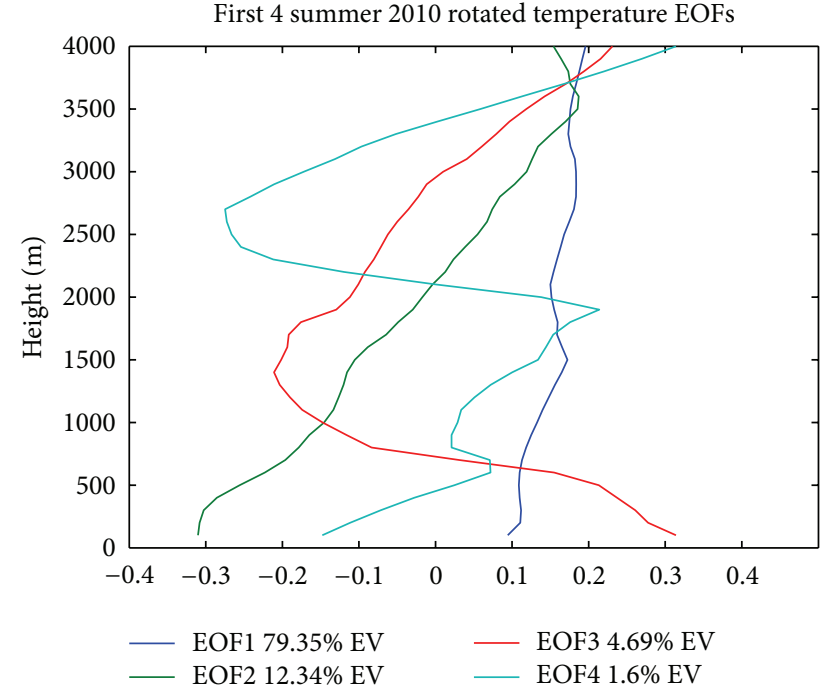

(b)

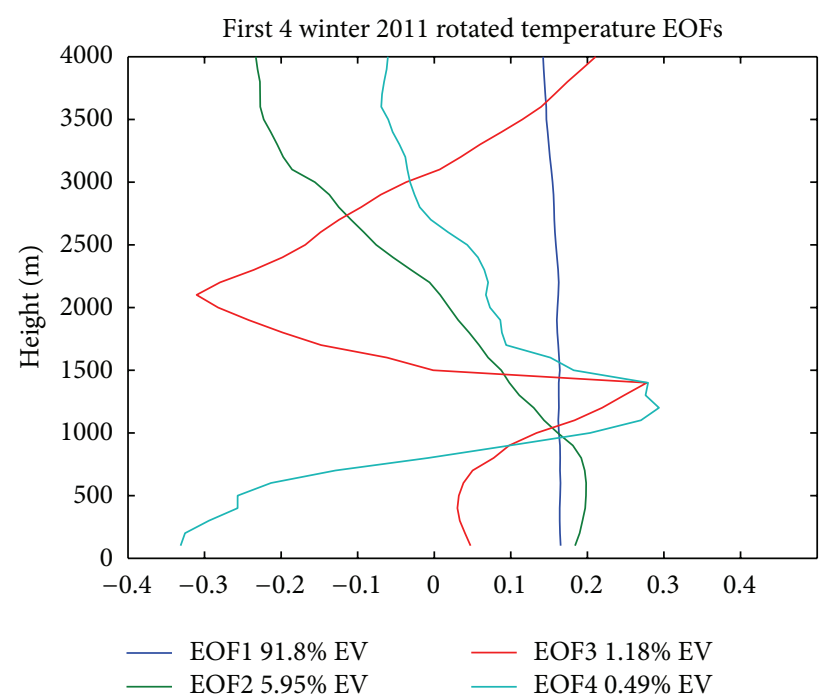

(d)

FIGURE 4: Rotated empirical orthogonal function (EOF) pattern vectors for vertical temperature profiles from 06UTC (15LST) radiosonde observations at Osan in four seasons: spring 2011 (a), summer 2010 (b), fall 2010 (c), and winter 2011 (d).

3.2. Model Evaluation at Osan. To measure the performance of the PBLH produced by the KWRF Model, a point-topoint comparison was conducted at the Osan site where the two types of observation datasets are available. The results are summarized in the form of a scatter diagram (Figure 5) where each point represents the monthly DMMH value. The linear regression equations on the plot provide information on the relationship between the model and the observed DMMHs and indicate how well the KWRF Model DMMHs are compared to the observed.

Figure 5(a) shows the scatter plot that compares the monthly KWRF DMMH with the 10-year average data (CB98). One merit of the CB98 dataset is its very low data loss because it was computed on a thermodynamic diagram using the parcel method. It can be seen that while the model
$\mathrm{DMMH}$ tended to be less than the observed, they have remarkable correlation (0.7). It shows that $70 \%$ of the variance in the KWRF DMMH values is explained by the 10 -year climatological values, and $30 \%$ of those differences remain unexplained. But the regression equation has a slope greater than 1 and a large offset $(\sim 830 \mathrm{~m})$. This means that the model simulates the observed pattern quite well, but not for the magnitude. The large offset should not be considered critical because CB98 is much smoothed data by using a 10 -year averaging.

Figure 5(b) shows the scatter plot between the monthly KWRF DMMH and the RAOB DMMH data for one year except the summertime rainy season (July-August 2010), when RAOB estimates of DMMH are nearly unavailable and substantially inaccurate due to bad weather conditions like 


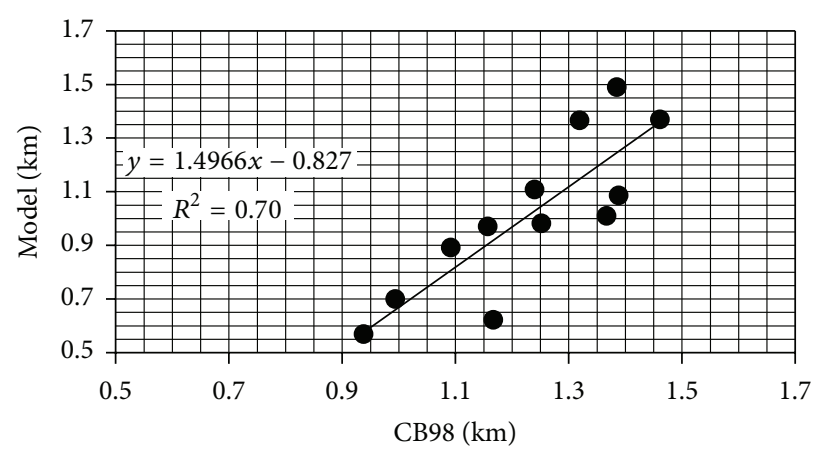

(a)

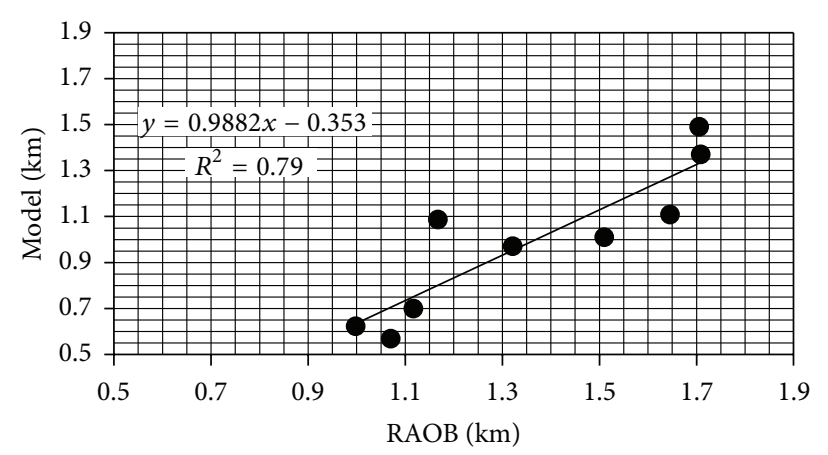

(b)

FIGURE 5: Comparison of monthly mean PBLH. The same KWRF Model PBLH is evaluated by (a) 10-year radiosonde data [18] and (b) 1-year (June 2010-May 2011) radiosonde data [19]. In (b), summer season RAOB data were not used due to low availability as a result of monsoon precipitation.

precipitation and strong winds. It shows that $79 \%$ of the variance in the KWRF DMMH values is explained by the 1year radiosonde-estimated values. The line in the graph has a slope of $\sim 1$, and an offset $(\sim 353 \mathrm{~m})$ smaller than CB98. This means that, compared to CB98, the KWRF model exhibits better agreement with RAOB in terms of magnitude and pattern.

In order to determine the probability that the computed correlation occurred by chance, we conducted a significance test using a two-tailed test based on the mutually exclusive hypothesis with the common significance level $(=0.05)$ and the degrees of freedom $(=10)$ and found that the critical value is $\sim 0.58$. Since the two correlation values in Figure 5 are greater than 0.58 , we can conclude that they are statistically significant and the probability of a chance occurrence is less than 5 out of 100 .

It is noted from Figure 5 that overall the model DMMHs tend to be lower than the radiosonde estimates with negative offsets. The model's underestimation of PBL height in the present study is firstly because the sounding data were mainly from clear days, while the modeled PBLH data were from all days. Second, the radiosonde-estimated DMMH is a point value, whereas the model DMMH represents a grid box $(10 \mathrm{~km} \times 10 \mathrm{~km})$ average, so model-gridded values of DMMH and large locality of radiosonde sounding can cause the lower model DMMH than the observed. Third, the KWRF model itself can have systematic errors in simulating boundary layer depth. Lastly, there can be potential error sources including an incorrect land-cover type and topographic effects in the model. This underestimating tendency is opposite to some studies (e.g., [39]) where the WRF with YSU PBL tend to overestimate the PBL depth. However, the overestimation of PBL height is somewhat unclear in other studies. For example, Shin and Hong [40] showed that YSU PBL had the second lowest depth during daytime among two nonlocal schemes and three local schemes. Such an overestimating or underestimating tendency seems to be dependent on observational system as well (e.g., radiosonde, wind profilers, LIDAR, etc.) used in the PBL height evaluation. When all these things are considered, the levels of correlation and offset shown in this section are acceptable.

\section{Horizontal Distribution of the Model Boundary Layer Height}

4.1. Diurnal Range and Morning Growth Rates. For simplicity, the diurnal range (daily maximum minus daily minimum) of PBLH is defined by 15LST PBLH minus 03LST PBLH. Figure 6 shows the spatial distribution of the diurnal range of PBLH by season. Overall, it shows that the PBLH field is influenced by seasonality and topographic characteristics. Compared to land PBLH, the maritime PBLH shows the lowest diurnal range values because of the ocean's large heat capacity and the marine boundary layer it develops, and these two effects can even lead to negative values at some local points (e.g., southeastern sea of the peninsula in fall) due to the time-lagged cycles of PBLH over land and ocean.

However, the diurnal range increases sharply inland and exceeds $1000 \mathrm{~m}$ over relatively low terrain including over the cities of Seoul, Daejeon, and Daegu in the warm season. Over land, springtime has the largest diurnal amplitude throughout the peninsula. Summertime also showed large diurnal amplitudes, but the spatial coverage was restricted within Republic of Korea. In summer, the spatial gradients and horizontal heterogeneity of diurnal range become large and this results in the largest diurnal range occurring around Seoul. A strong gradient was seen over the western shoreline near Seoul city where the diurnal amplitude varies from a low of $\sim 25 \mathrm{~m}$ to values of 1000-1500 m. The difference in spatial heterogeneity of diurnal range is related to heavy rainfall in the rainy season during summertime and frequent clear skies in springtime. Wintertime has the smallest diurnal amplitude especially over mountainous areas. Fall has features intermediate between summer and winter in time and space.

Figure 7 shows the morning growth rate of $\mathrm{PBLH}$, which is defined by 12LST PBLH minus 06LST PBLH. The growth rate of the $\mathrm{PBLH}$ during the morning hours is an important factor in the development of high ozone concentrations at ground level (Berman et al., [41]). Overall, the growth rate has similar patterns to the diurnal range in its horizontal distribution. Both Koreas show similar growth rates in spring, but in summer Republic of Korea showed more rapid growth rates than Democratic People's Republic of Korea. The largest 


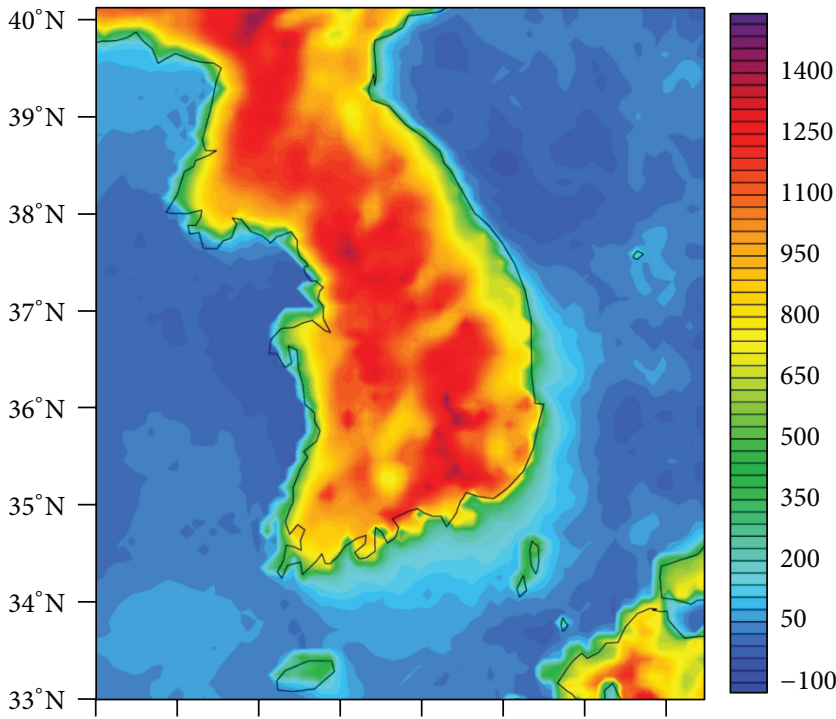

$124^{\circ} \mathrm{E} 125^{\circ} \mathrm{E} 126^{\circ} \mathrm{E} 127^{\circ} \mathrm{E} 128^{\circ} \mathrm{E} 129^{\circ} \mathrm{E} 130^{\circ} \mathrm{E} 131^{\circ} \mathrm{E}$ (a) Spring

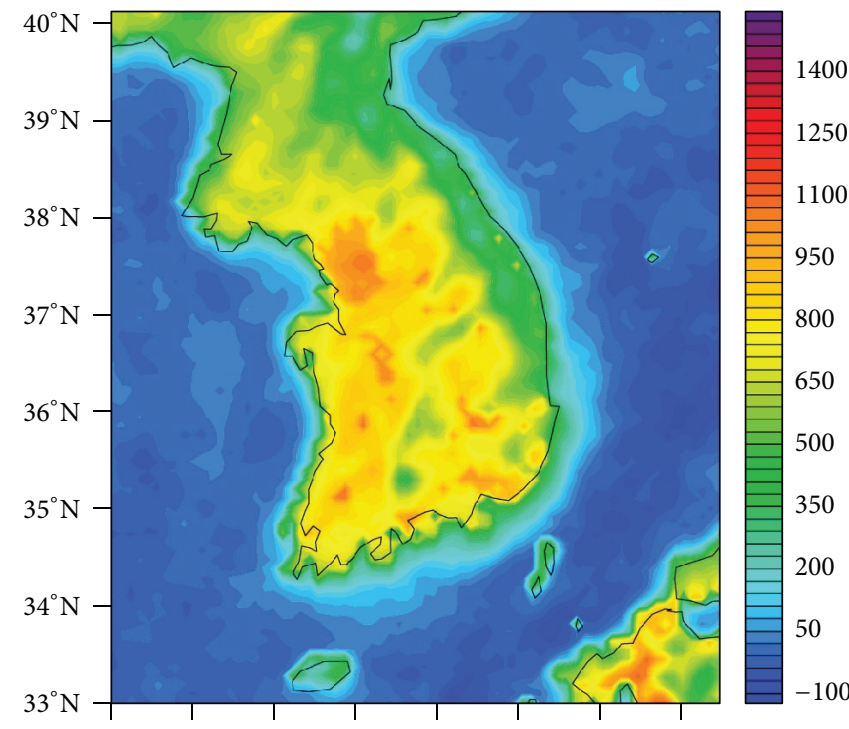

$124^{\circ} \mathrm{E} 125^{\circ} \mathrm{E} \quad 126^{\circ} \mathrm{E} \quad 127^{\circ} \mathrm{E} 128^{\circ} \mathrm{E} 129^{\circ} \mathrm{E} \quad 130^{\circ} \mathrm{E} 131^{\circ} \mathrm{E}$

(c) Fall

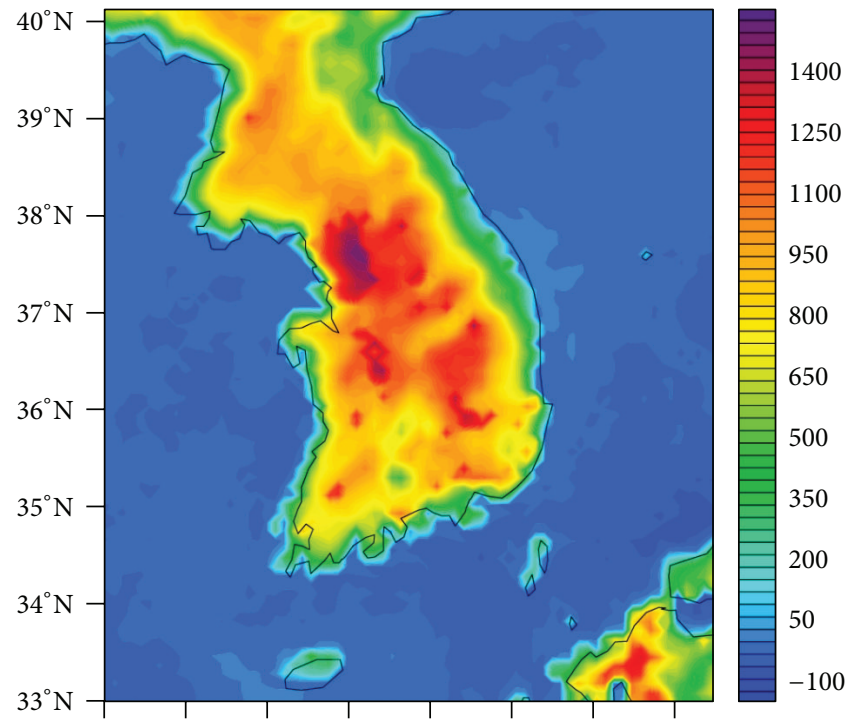

$124^{\circ} \mathrm{E} 125^{\circ} \mathrm{E} \quad 126^{\circ} \mathrm{E} \quad 127^{\circ} \mathrm{E} \quad 128^{\circ} \mathrm{E} \quad 129^{\circ} \mathrm{E} \quad 130^{\circ} \mathrm{E} \quad 131^{\circ} \mathrm{E}$

(b) Summer

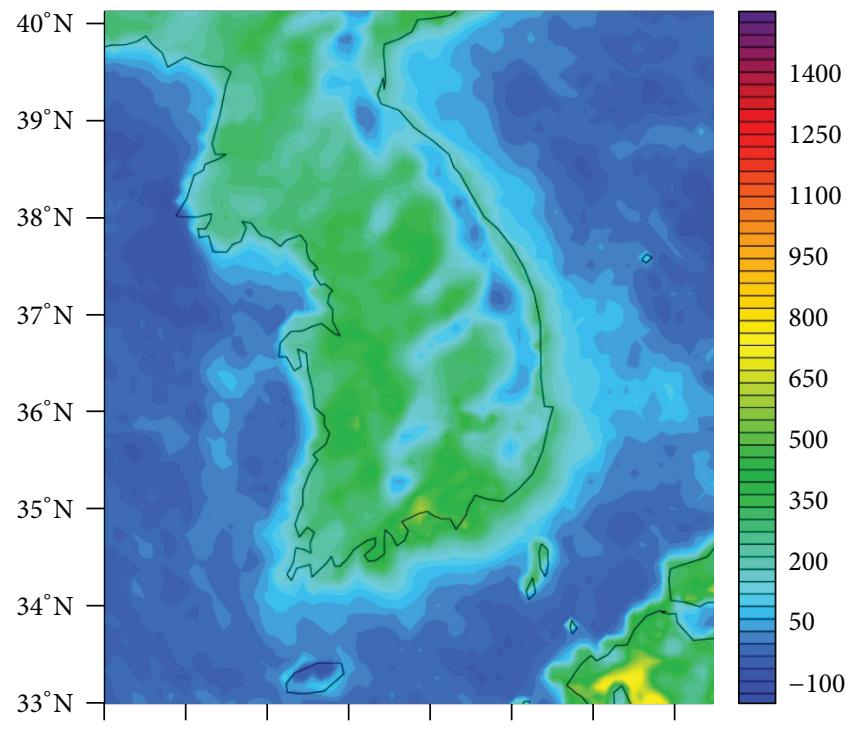

$124^{\circ} \mathrm{E} 125^{\circ} \mathrm{E} \quad 126^{\circ} \mathrm{E} 127^{\circ} \mathrm{E} \quad 128^{\circ} \mathrm{E} 129^{\circ} \mathrm{E} 130^{\circ} \mathrm{E} 131^{\circ} \mathrm{E}$

(d) Winter

FIGURE 6: Seasonal mean distributions of the diurnal range of PBLH over the Southern Korean Peninsula and surrounding ocean during the period June 2010-May 2011.

growth rates appeared inland over large cities and mountain valleys, where they exceeded $1100 \mathrm{~m}$ at some locations. Growth rates over high mountain ranges were lower $(\sim 500 \mathrm{~m})$ and declined rapidly as the shoreline is approached, with values of a few tens of meters along the coastline. This pattern is consistent with the findings of Berman et al. [41] that the effect of the marine boundary layer is to depress surface temperature and thermal convection. Values of zero or negative growth rates appearing over much of the ocean indicate that the direct effect of incoming solar radiation is very small on the PBL development at those areas over the sea. Spatial distributions of nocturnal PBLH showed very little seasonal variation and they were not shown.
4.2. Daily Maximum Mixing Height (DMMH). Since the PBLH data used in this study have a 3-hour resolution, 06UTC (15LST) PBLH can be regarded as DMMH, which usually corresponds to maximum afternoon mixing depth in the case of no-precipitation days. Figure 8 displays the horizontal distribution of DMMH for the seasonal mean. In general, the daytime boundary layer is deeper over land as expected except winter. Large DMMHs can be found in nonmountainous regions such as the Seoul and Daegu metropolitan cities. This is related to the urban heat island effect as shown by Kim and Baik (2005) [42] and Lee and Kim [43]. In winter, however, the boundary depths are larger over the ocean, and this can be easily understood from the 


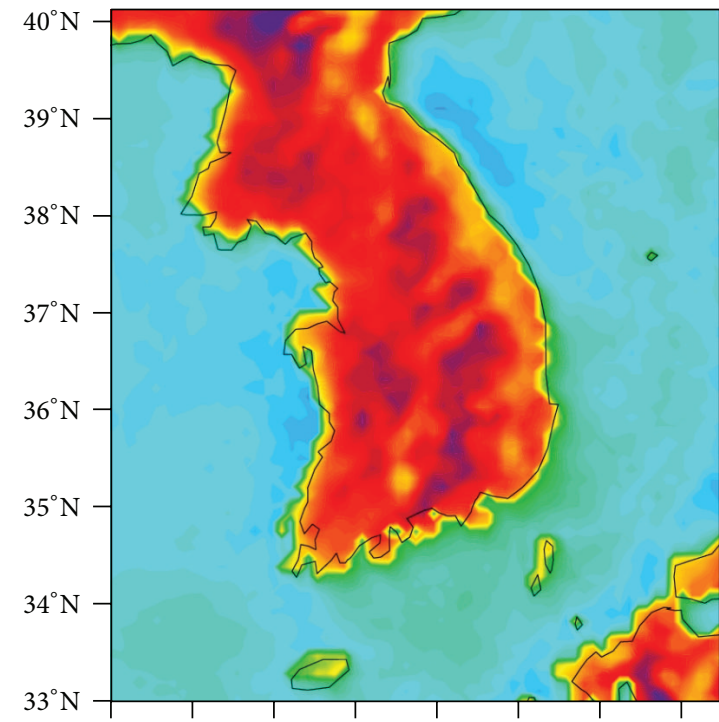

$124^{\circ} \mathrm{E} 125^{\circ} \mathrm{E} 126^{\circ} \mathrm{E} 127^{\circ} \mathrm{E} 128^{\circ} \mathrm{E} 129^{\circ} \mathrm{E} 130^{\circ} \mathrm{E} 131^{\circ} \mathrm{E}$ (a) Spring

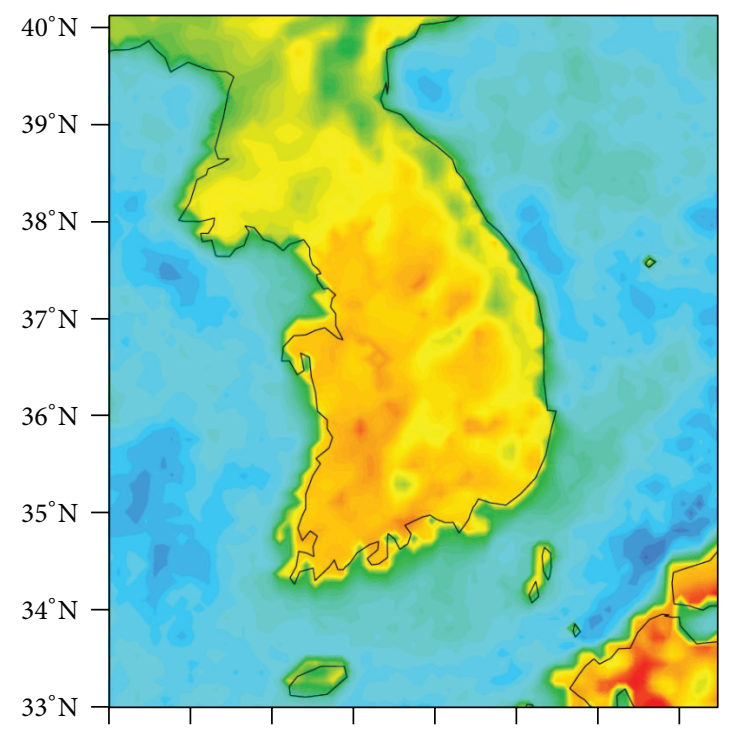

$124^{\circ} \mathrm{E} 125^{\circ} \mathrm{E} 126^{\circ} \mathrm{E} 127^{\circ} \mathrm{E} 128^{\circ} \mathrm{E} 129^{\circ} \mathrm{E} 130^{\circ} \mathrm{E} 131^{\circ} \mathrm{E}$

(c) Fall

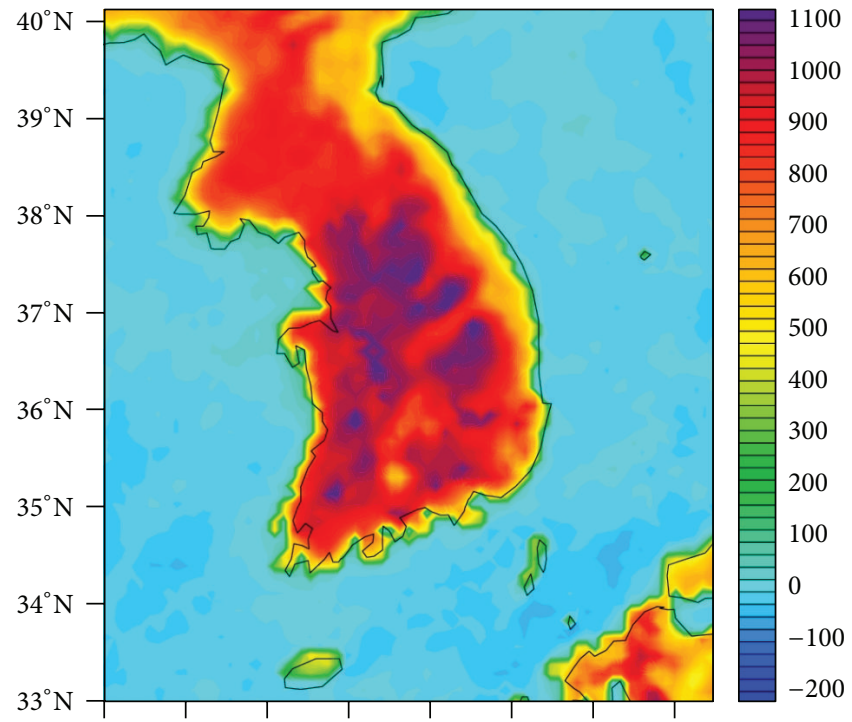

$124^{\circ} \mathrm{E} 125^{\circ} \mathrm{E} \quad 126^{\circ} \mathrm{E} \quad 127^{\circ} \mathrm{E} \quad 128^{\circ} \mathrm{E} \quad 129^{\circ} \mathrm{E} \quad 130^{\circ} \mathrm{E} \quad 131^{\circ} \mathrm{E}$

(b) Summer

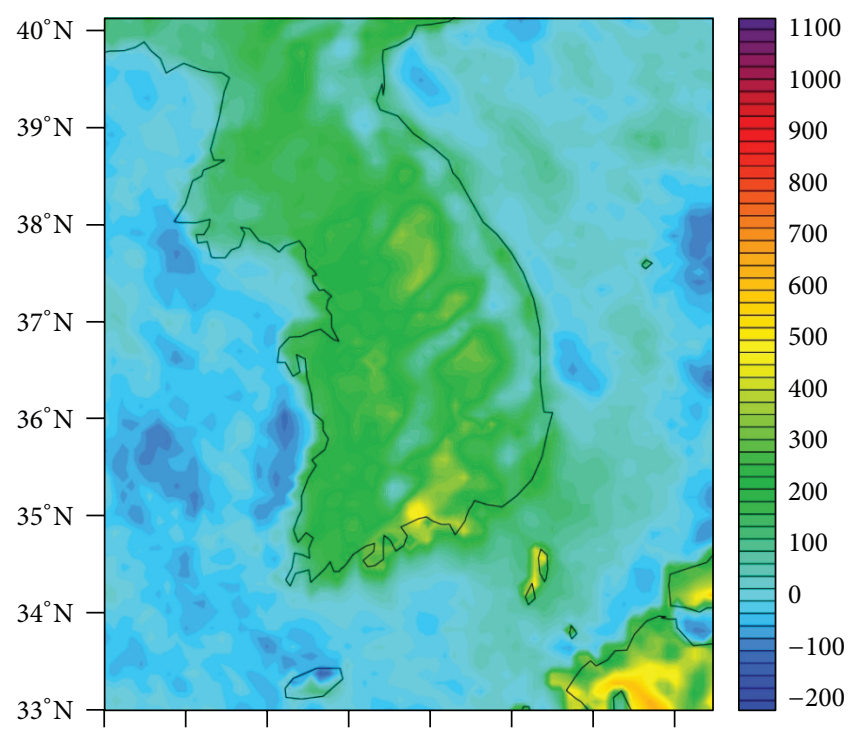

$124^{\circ} \mathrm{E} 125^{\circ} \mathrm{E} 126^{\circ} \mathrm{E} 127^{\circ} \mathrm{E} 128^{\circ} \mathrm{E} 129^{\circ} \mathrm{E} 130^{\circ} \mathrm{E} 131^{\circ} \mathrm{E}$

(d) Winter

Figure 7: Same as Figure 6, but for morning growth rate of PBLH.

relatively high sea surface temperature due to the larger heat capacity of the sea.

Over the sea, the wintertime marine PBL depths are smaller in the West Sea than in the East Sea and tend to be smaller at high latitudes. This is affected mainly by the sea surface temperature distribution. Over land, the topographic effect is clearly seen regardless of season, especially along the high mountain ranges. This results in relatively low DMMHs in the mountainous areas in all seasons and reflects that the mountains have cooler daytime surface temperatures.

Figure 9 shows seasonal standard deviation of DMMH. It should be noticed that seacoast areas, especially the southeastern areas, show large variability in DMMH in spring. In the other seasons, low-altitude regions show large variability compared to high-altitude regions. Over sea, the variability of DMMH is generally small compared to land, except for spring.

\section{Frequency Distribution and Monthly Variation of the Model Boundary Layer Height at Two Local Points}

5.1. Frequency Distribution of PBLH and DMMH. In order to see the distribution of PBLH data at all times of day ( $3 \mathrm{~h}$ interval) during the one-year period, histograms of PBLHs were 


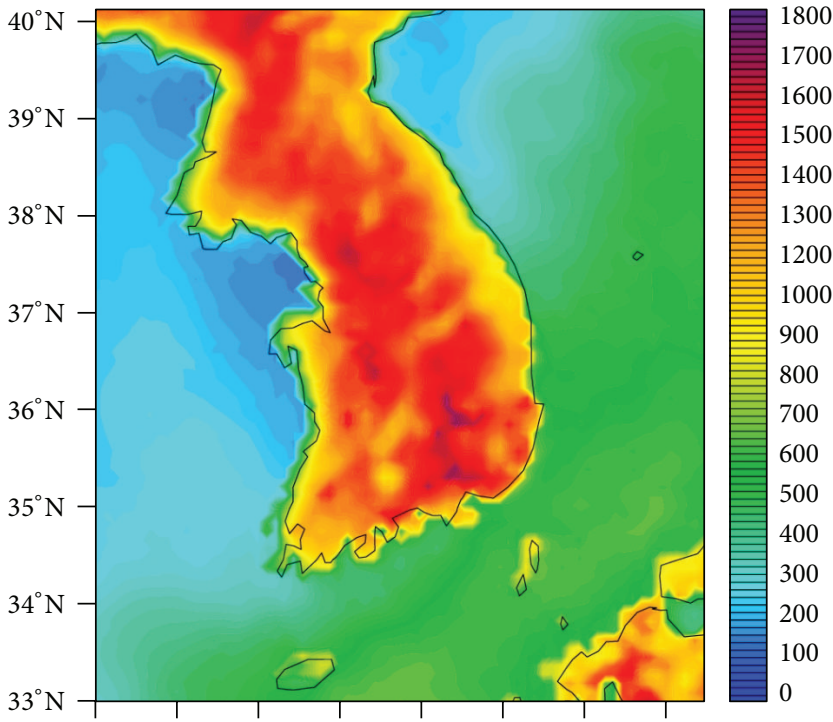

$124^{\circ} \mathrm{E} 125^{\circ} \mathrm{E} 126^{\circ} \mathrm{E} 127^{\circ} \mathrm{E} 128^{\circ} \mathrm{E} \quad 129^{\circ} \mathrm{E} \quad 130^{\circ} \mathrm{E} 131^{\circ} \mathrm{E}$ (a) Spring

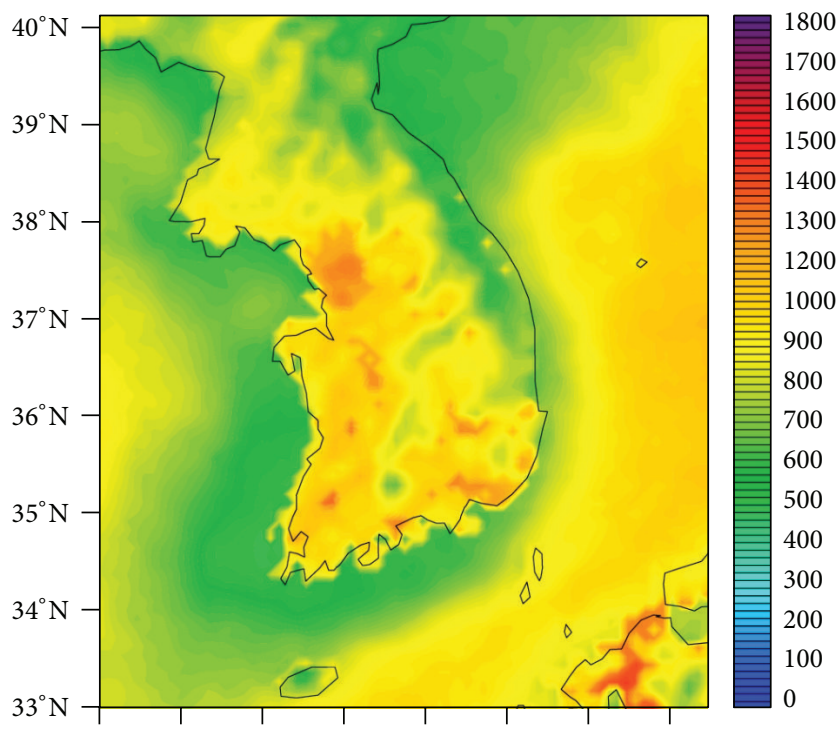

$124^{\circ} \mathrm{E} 125^{\circ} \mathrm{E} 126^{\circ} \mathrm{E} 127^{\circ} \mathrm{E} 128^{\circ} \mathrm{E} 129^{\circ} \mathrm{E} 130^{\circ} \mathrm{E} 131^{\circ} \mathrm{E}$

(c) Fall

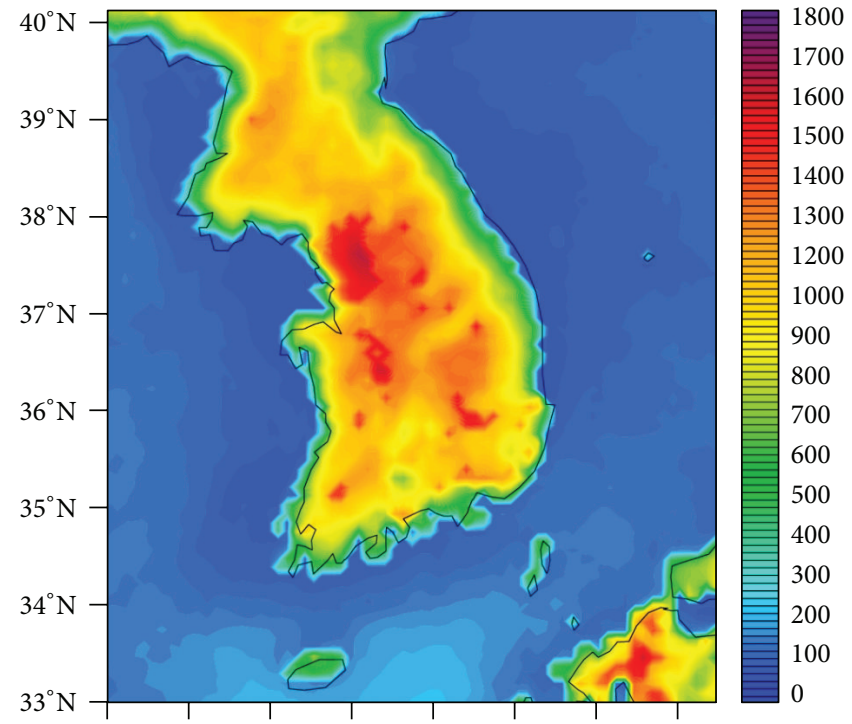

$124^{\circ} \mathrm{E} 125^{\circ} \mathrm{E} \quad 126^{\circ} \mathrm{E} \quad 127^{\circ} \mathrm{E} \quad 128^{\circ} \mathrm{E} \quad 129^{\circ} \mathrm{E} \quad 130^{\circ} \mathrm{E} \quad 131^{\circ} \mathrm{E}$

(b) Summer

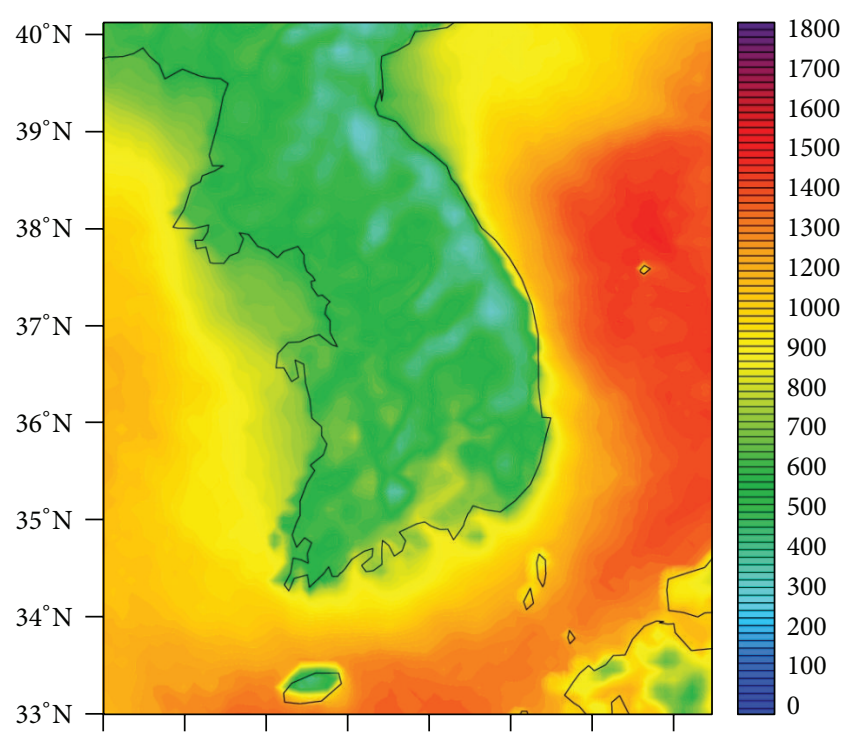

$124^{\circ} \mathrm{E} 125^{\circ} \mathrm{E} 126^{\circ} \mathrm{E} 127^{\circ} \mathrm{E} 128^{\circ} \mathrm{E} 129^{\circ} \mathrm{E} 130^{\circ} \mathrm{E} 131^{\circ} \mathrm{E}$

(d) Winter

FIgURE 8: Seasonal mean distributions of the DMMH over the Southern Korean Peninsula and surrounding ocean during the period June 2010-May 2011.

calculated in Figure 10 for Osan and Gwangju (see Figure 2). It shows the frequency of PBLH more quantitatively using the same bin width as Choi and Baek [18]. First of all, it can be seen that the occurrence frequency is high (low) for smaller (larger) PBLH bins. The frequency distribution of PBLH appears to follow approximately exponential distributions regardless of season. Both sites show the largest frequency in $100-500 \mathrm{~m}$ bin, occupying a relative frequency of $\sim 44 \%$.

Figure 11 shows histograms of DMMHs for the two sites and provides detailed information on occurrence frequency and relative frequency of DMMH for each site. They reveal that the frequency of DMMH at Osan (Gwangju) had the most occurrences in the $500-1000 \mathrm{~m}(1000-1500 \mathrm{~m})$ bin, occupying relative frequency of $\sim 62(56) \%$. Unlike Figure 10, the histograms are somewhat close to Gaussian distributions and this characteristic is more clear at Gwangju in the fall season. In summer, the shape of the distribution is considerably broader, implying larger variability. In winter, the distribution is skewed toward low DMMH values and deviates from the Gaussian-like shape.

The one-year mean DMMH at the two sites shows again a Gaussian-like distribution (Figure 11(e)). Gwangju shows relatively lower (higher) frequency at small (large) PBLH bins, compared to Osan. Possible reasons include that 


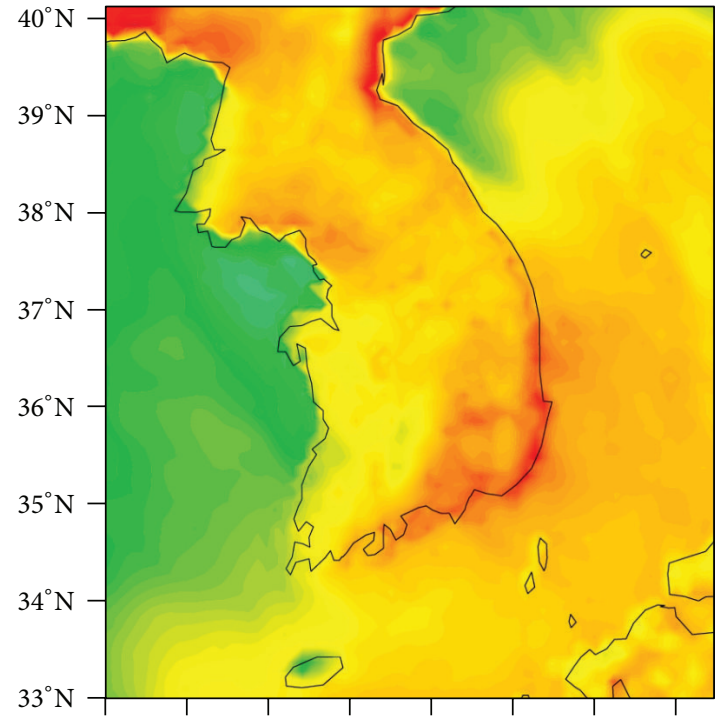

$124^{\circ} \mathrm{E} 125^{\circ} \mathrm{E} \quad 126^{\circ} \mathrm{E} \quad 127^{\circ} \mathrm{E} \quad 128^{\circ} \mathrm{E} \quad 129^{\circ} \mathrm{E} \quad 130^{\circ} \mathrm{E} \quad 131^{\circ} \mathrm{E}$

(a) Spring

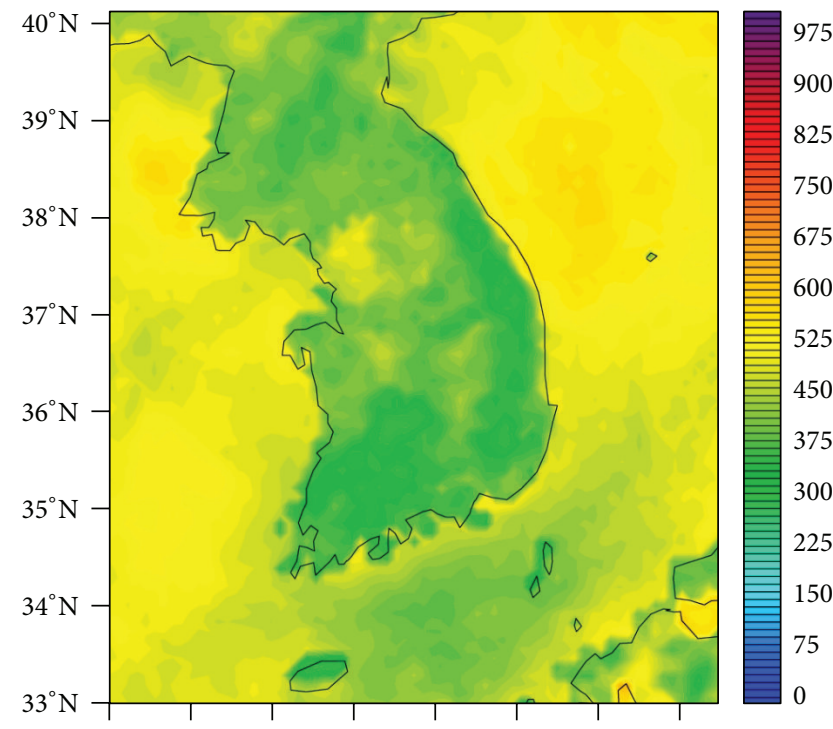

$124^{\circ} \mathrm{E} 125^{\circ} \mathrm{E} \quad 126^{\circ} \mathrm{E} \quad 127^{\circ} \mathrm{E} \quad 128^{\circ} \mathrm{E} 129^{\circ} \mathrm{E} 130^{\circ} \mathrm{E} \quad 131^{\circ} \mathrm{E}$

(c) Fall

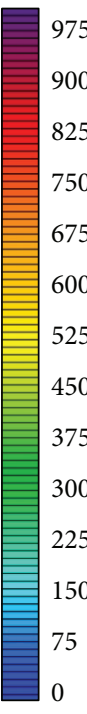

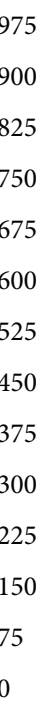

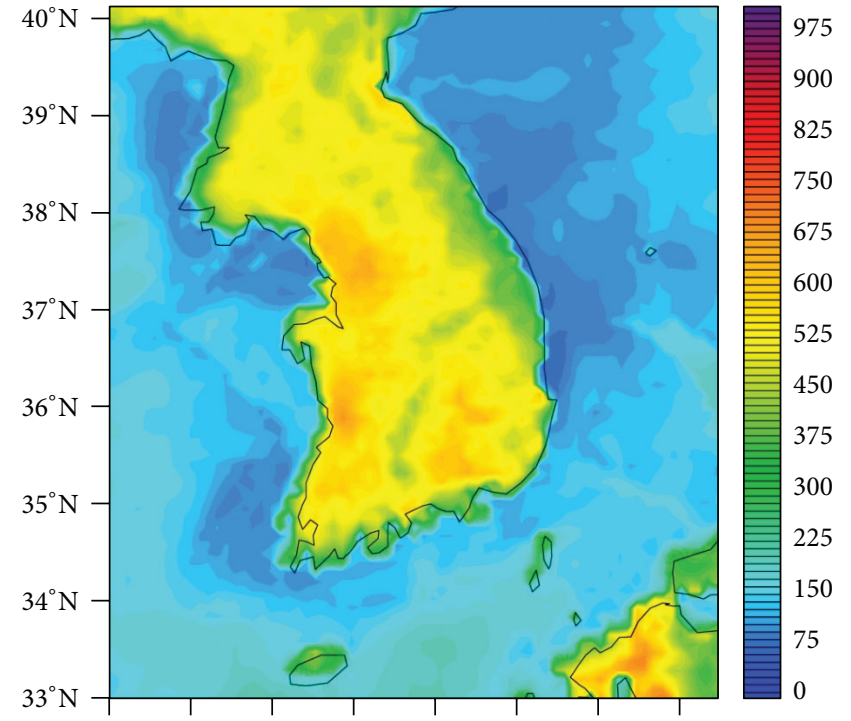

$124^{\circ} \mathrm{E} 125^{\circ} \mathrm{E} 126^{\circ} \mathrm{E} 127^{\circ} \mathrm{E} 128^{\circ} \mathrm{E} 129^{\circ} \mathrm{E} 130^{\circ} \mathrm{E} 131^{\circ} \mathrm{E}$

(b) Summer

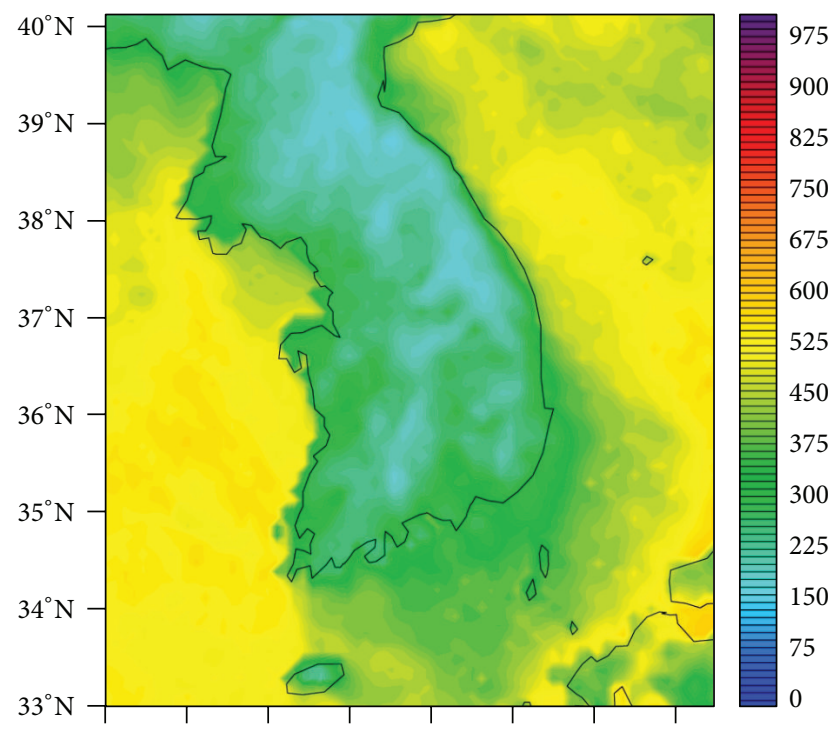

$124^{\circ} \mathrm{E} 125^{\circ} \mathrm{E} 126^{\circ} \mathrm{E} 127^{\circ} \mathrm{E} 128^{\circ} \mathrm{E} 129^{\circ} \mathrm{E} 130^{\circ} \mathrm{E} 131^{\circ} \mathrm{E}$

(d) Winter

FIGURE 9: Same as Figure 8, except for DMMH's standard deviation.

Gwangju is geographically located south of Osan and thus climatologically warmer than Osan or that Gwangju is more unstable and convective than Osan during the daytime. Also, the Gwangju site showed a pattern more similar to a Gaussian distribution and had its mode near $1100 \mathrm{~m}$. The Osan site shows larger skewness than Gwangju site and has its first mode at $900 \mathrm{~m}$. The second peak at a height of $300 \mathrm{~m}$ at both sites is an interesting feature and remains for further analysis.

5.2. Monthly and Diurnal Variation of DMMH. In order to see the temporal trend in model DMMH, monthly and seasonal mean and standard deviation were calculated. Table 1 shows that the highest DMMH occurs in the spring season at both sites, and the spring mean value is $\sim 1315 \mathrm{~m}(1406 \mathrm{~m})$ for the Osan (Gwangju) site. The lowest DMMH appears in the winter season at both sites, and the winter mean value is $\sim 630 \mathrm{~m}(691 \mathrm{~m})$ for Osan (Gwangju) site. Summer and fall seasons show intermediate values of DMMH between the spring and winter values. Summer DMMH values are most spread out and the standard deviation is large, indicating that summer has the largest variability in the DMMH dynamics compared to the other seasons, whereas winter DMMHs are least spread out and show the smallest dispersion in DMMH. Compared with Choi and Baek [18], the most different aspect is that the KWRF DMMH is much smaller in winter. This 


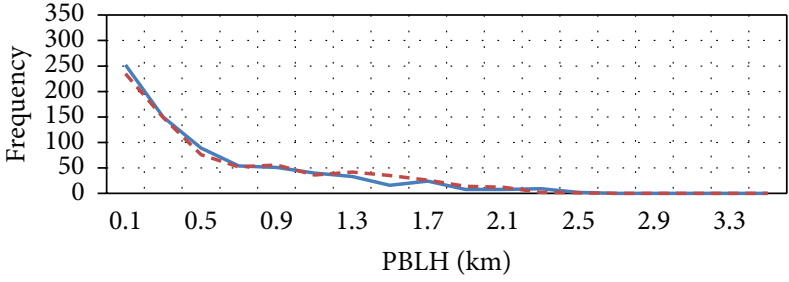

(a) Spring

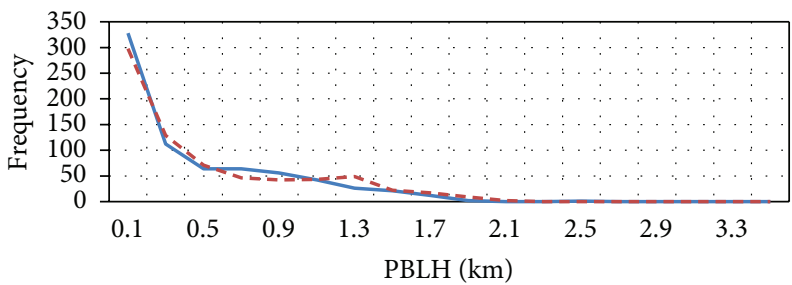

(c) Fall

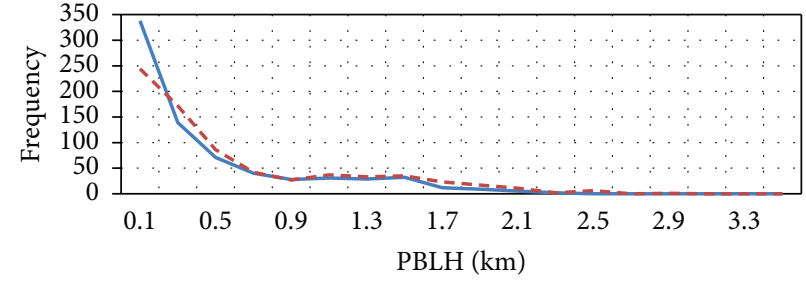

(b) Summer

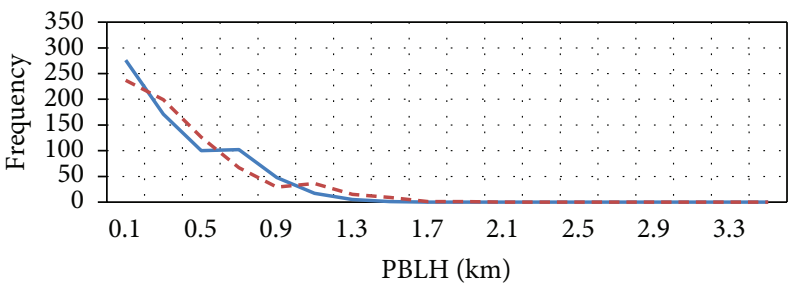

(d) Winter

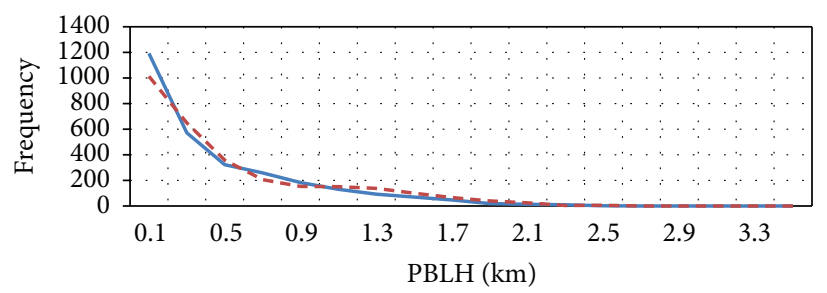

(e) 1 year

Figure 10: Histogram of model PBLH at Osan and Gwangju for one year (June 2010-May 2011). The solid (dashed) line denotes Osan (Gwangju) site.

TABLE 1: Monthly and seasonal mean and standard deviation (SD) of model DMMH (m).

\begin{tabular}{lcc}
\hline Month/season & Osan & Gwangju \\
& Mean \pm SD & Mean \pm SD \\
\hline 6 & $1365.58 \pm 596.40$ & $1606.47 \pm 698.37$ \\
7 & $892.19 \pm 532.82$ & $1190.51 \pm 466.21$ \\
8 & $981.90 \pm 509.45$ & $1402.53 \pm 496.75$ \\
Summer & $1079.89 \pm 583.80$ & $1399.84 \pm 586.61$ \\
9 & $1107.41 \pm 463.84$ & $1395.94 \pm 399.16$ \\
10 & $1010.00 \pm 359.50$ & $1390.61 \pm 290.33$ \\
11 & $970.64 \pm 329.33$ & $1117.86 \pm 303.54$ \\
Fall & $1029.35 \pm 393.23$ & $1301.47 \pm 358.30$ \\
12 & $568.32 \pm 354.05$ & $777.50 \pm 404.96$ \\
1 & $699.47 \pm 251.95$ & $611.13 \pm 251.20$ \\
2 & $621.65 \pm 281.01$ & $683.28 \pm 389.78$ \\
Winter & $629.81 \pm 295.67$ & $690.64 \pm 348.65$ \\
3 & $1490.01 \pm 481.42$ & $1490.19 \pm 420.74$ \\
4 & $1369.71 \pm 557.96$ & $1408.14 \pm 553.90$ \\
5 & $1086.14 \pm 595.12$ & $1318.98 \pm 590.12$ \\
Spring & $1315.29 \pm 572.62$ & $1405.77 \pm 531.02$ \\
\hline
\end{tabular}

indicates that the model PBL mixing is generally weak in the cold season and presumably nighttime stable regimes.
Figure 12 shows variations in monthly mean DMMH at Osan and Gwangju with standard deviations denoted by the vertical error bars. Overall, the two sites show a similar behavior in the pattern and magnitude. The monthly mean DMMHs are high in March and June at both sites, forming two peaks in the graphs, due to fair weather conditions in spring and early summer. From December to January both sites exhibit the lowest values, and this is basically attributed to low surface temperature due to small insolation in the winter season. The lowest values are $\sim 600 \mathrm{~m}$ and the highest values go over $1500 \mathrm{~m}$, making the maximum seasonal differences as large as $\sim 900 \mathrm{~m}$.

It should be noted that there are two depressions of the mean DMMHs in May and July during the warm season. The one depression in July is clearly related to the increase of cloud cover and precipitation during the monsoon season (normally late June through early August in Korea), as shown in Figure 13(a). The large amount of precipitation at Osan in September 2010 was caused by the 21-September heavy rainfall event which occurred in the central part of the Korean peninsula (see the satellite image in Figure 13(b)). It can be seen that the record-breaking heavy rainfall contributed to lower the mean DMMH more at Osan than at Gwangju. This can be confirmed also by examining vertical radiosonde soundings measured at both sites on September 21, 2010. Figure 14 shows that Gwangju had a normal mixed layer with a depth of $1385 \mathrm{~m}$ on the day, whereas Osan had a 


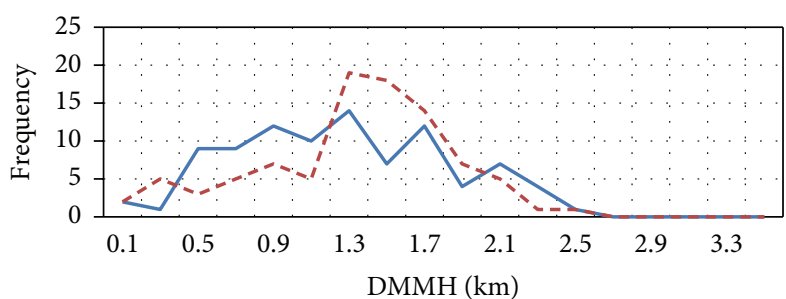

(a) Spring

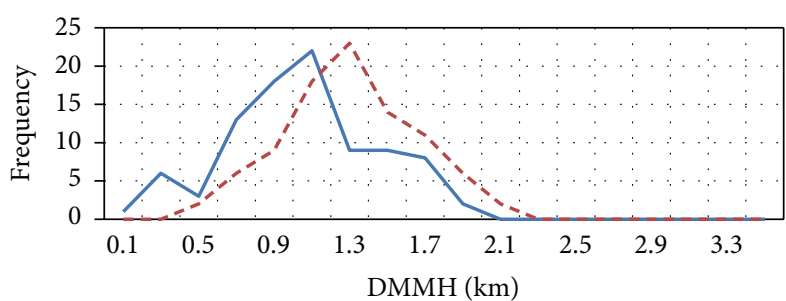

(c) Fall

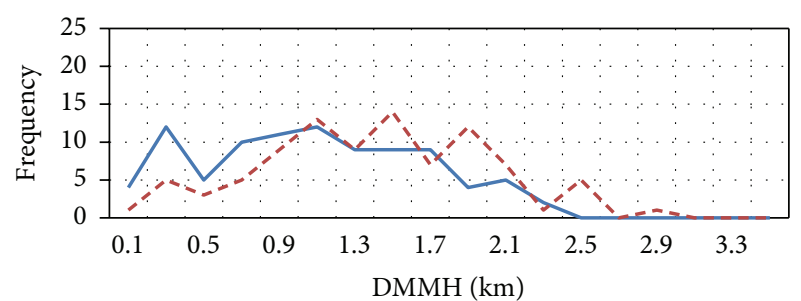

(b) Summer

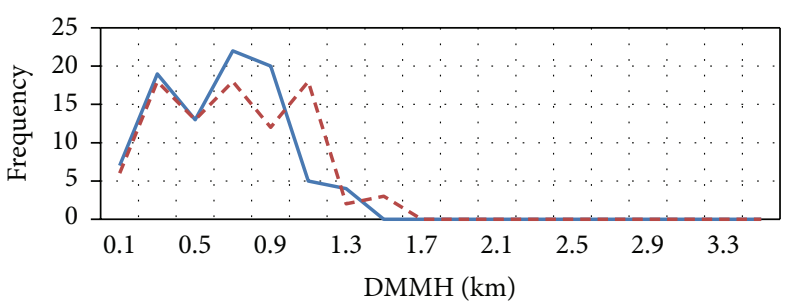

(d) Winter

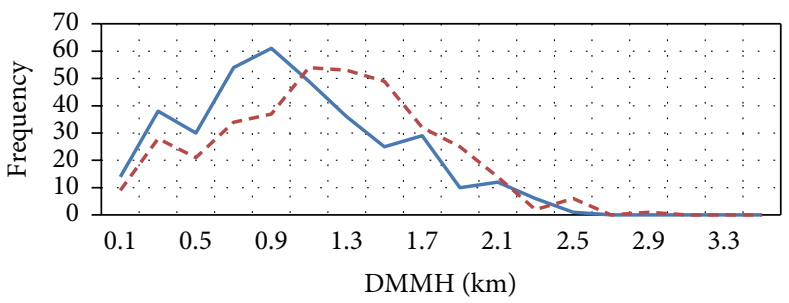

(e) 1 year

Figure 11: Same as Figure 10 except for model DMMH. The solid (dashed) line denotes Osan (Gwangju).
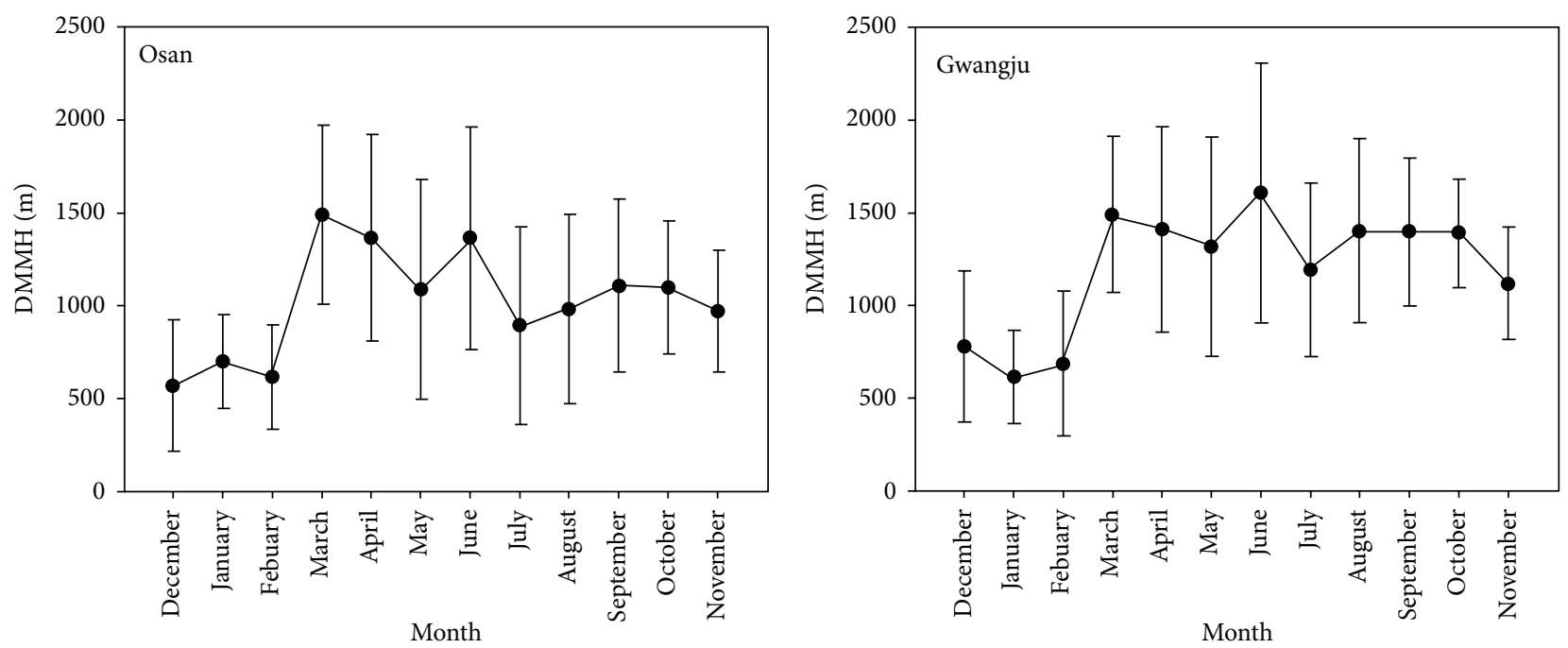

FIGURE 12: Monthly variation of mean and standard deviation of model DMMH at Osan and Gwangju for one year (June 2010-May 2011), which has re-arranged months for the $x$-axis label.

highly disturbed boundary layer with large wind speed and fluctuating vertical profiles.

On the other hand, the other depression in May is not related to monsoon rainfall. Figure 12 displays a decrease in monthly mean DMMH from March to May. This is associated with typical springtime changes in turbulent heat fluxes and surface wind over the Korean Peninsula. Figure 15 shows changes in monthly mean values of several micrometeorological variables measured at the Haenam Farmland site (KoFlux/AsiaFlux site code: HFK; refer to the web site http://asiaflux.net and http://ncam.kr/page/koflux/database for detailed information) from March to May 2011. It shows 


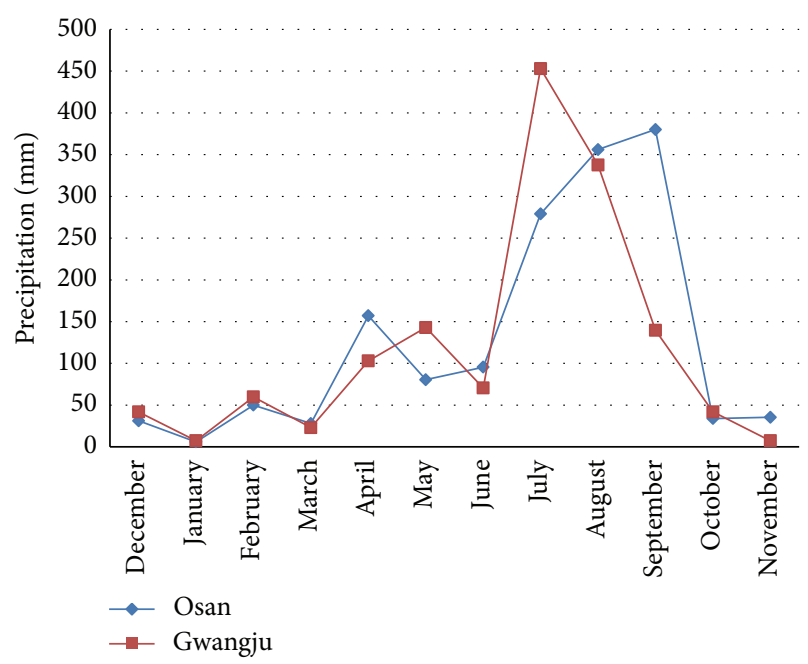

(a)

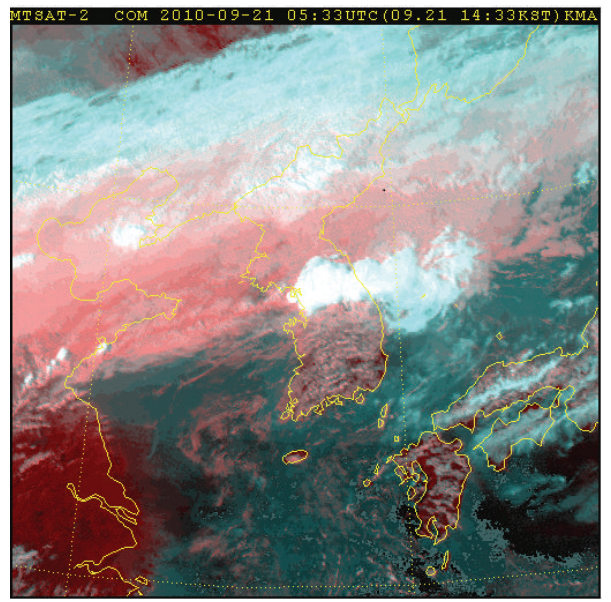

(b)

Figure 13: (a) Monthly mean precipitation observed at Osan and Gwangju during June 2010-May 2011 with re-arranged months for the $x$-axis label, and (b) the composite satellite image valid at 1433LST 21 September, 2010.

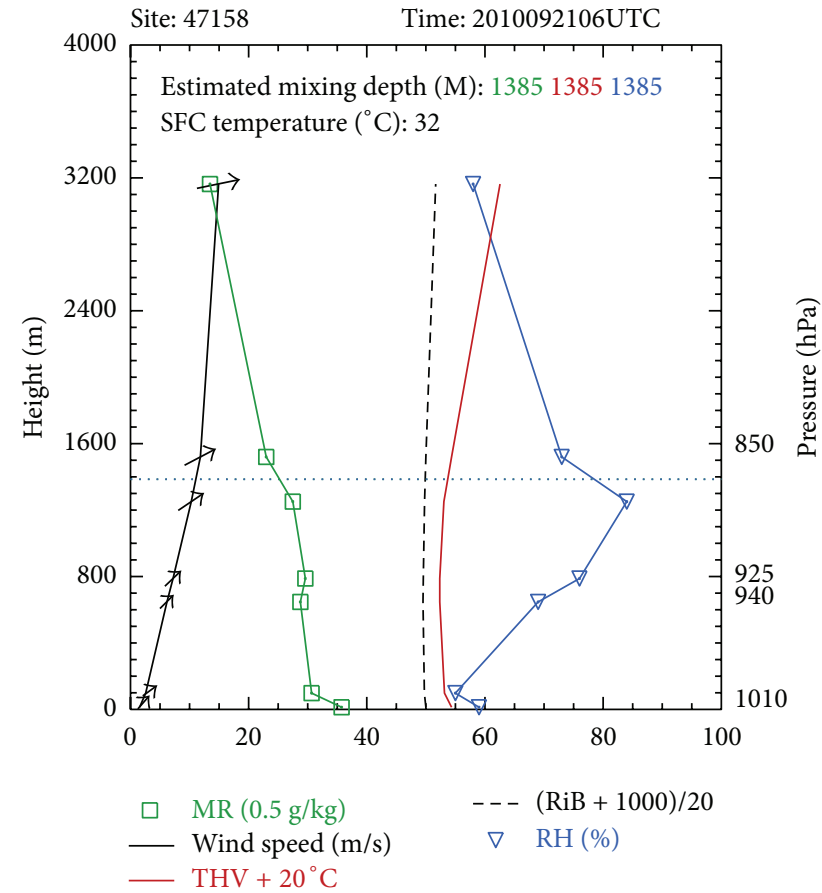

(a)

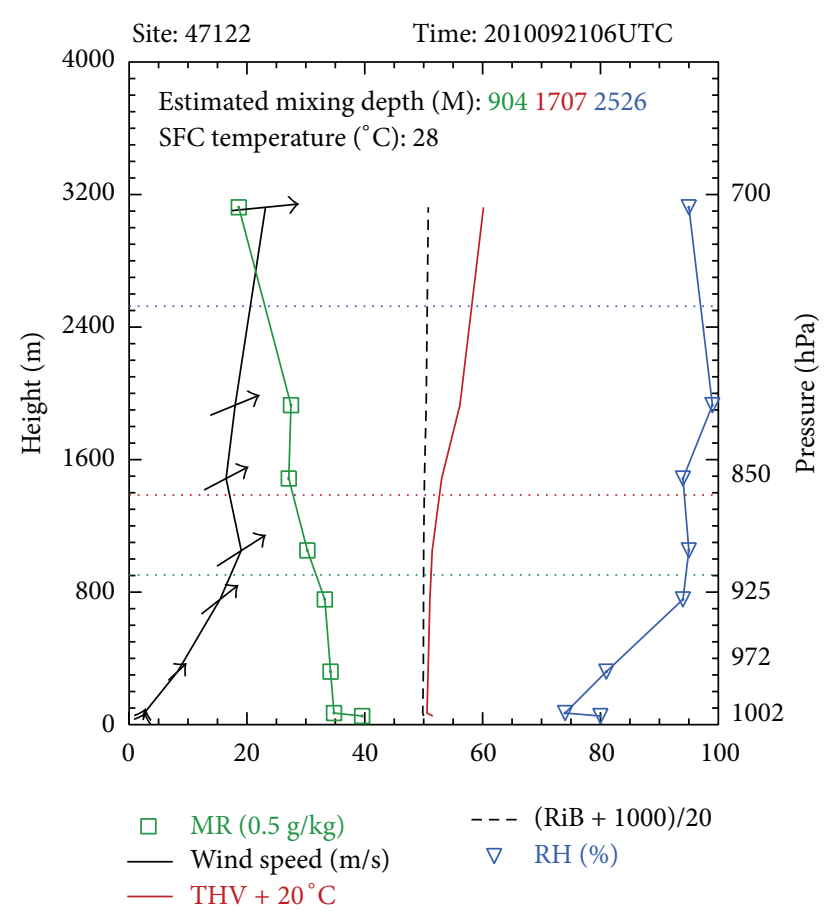

(b)

FIGURE 14: Vertical profiles of water vapor mixing ratio (MR), virtual potential temperature (THV), relative humidity (RH), horizontal wind speed, and the bulk Richardson number (RiB) measured at Gwangju (a) and Osan (b) radiosonde sites. The arrows denote horizontal winds at each level, and the horizontal dotted lines denote maximum gradient levels for each profile.

that evapotranspiration increased by $\sim 60 \%$ while sensible heat fluxes gradually decreased from March to May, resulting in decreasing in Bowen ratio. This indicates that plants started active growth and photosynthesis with transpiration depending on more insolation, allotting more energy toward latent heat rather than sensible heat as time goes by. The reduction in sensible heat fluxes leads to reduction in buoyancy. Wind speed also plays an important role in PBL depth through mechanical turbulence generation. Wind speed is one of the main variables that can identify the PBL depth under strongly convective conditions (e.g., Stull, [1]). Wind speed near the surface decreases from March, when the strongest near-surface winds occur due to frequently passing highpressure systems over the Korean Peninsula (e.g., [44, 45]), 


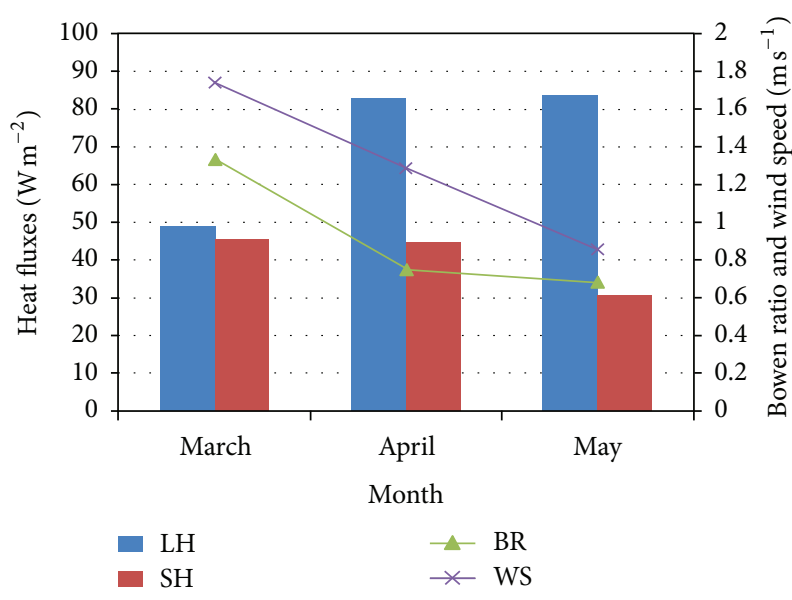

Figure 15: Changes in latent heat fluxes (LH), sensible heat fluxes $(\mathrm{SH})$, the dimensionless Bowen ratio (BR), and near-surface wind speed measured from March to May 2011 at the KoFlux Haenam site which is located near Gwangju.

to May. Thus, a reduction in both sensible heat fluxes and near-surface wind speed accounts for the depression of mean $\mathrm{DMMH}$ in May.

\section{Summary and Concluding Remarks}

Planetary boundary layer height is an important variable in modeling weather phenomena and air quality. Current understanding of the spatial distribution and temporal change of PBLH over the Korean Peninsula is very partial and incomplete. This paper uses short-term forecasts from the operational regional KWRF model to obtain information on the spatial distribution and temporal variations in PBLH that are unavailable with the current observations and analyses over the region. To validate the model, we make use of previously unpublished 15LST Korean radiosonde profiles. Their seasonal and vertical modes of variability are presented using EOF analysis.

Model integrations for June 2010-May 2011 suggest that PBLHs exhibited the largest diurnal range, morning growth rate and daytime maximum values over lower terrain inland in spring, with the smallest values over higher terrain in winter. Strong horizontal gradients of PBLH were observed along the coastline especially in summer. The surrounding ocean showed very low (even slightly negative) values in the diurnal range, morning growth rate, and daytime maximum fields of PBLHs due to its low surface temperature and thermally depressive marine boundary layers. Large DMMHs were located over nonmountainous regions (especially over the cities of Seoul, Daejeon, and Daegu as a result of the urban heat island) in spring, while the highest DMMHs were located over the East Sea and the South Sea in winter. Regarding the variability of $\mathrm{DMMH}$, it was large in the southeastern seacoast areas in spring and was small over all seas surrounding the peninsula in summer.

Local analyses of model PBLHs and DMMHs at the Osan and Gwangju points showed that histograms of model PBLH tended to have exponential distributions of frequency at both locations, while those of model DMMH exhibited almost Gaussian distributions especially at Gwangju. Monthly variation of DMMH had its main peaks in March and June and its lowest values in winter, with the largest variability in summer. There were two secondary minimums of DMMHs in May and July as well. The minimum DMMHs in winter and July are mainly attributed to the lowest surface temperature and the rainy season, respectively. It was suggested that the secondary minimum of mean DMMH in May can be accounted for by the decreasing trend in both Bowen ratio and near-surface wind speed during spring over the peninsula.

The current study provides meso- and regional scale analyses of PBLH fields over the Korean Peninsula for the first time. The complex structure of PBLH variation in space and time is reasonably shown using 3-hourly model forecasts for one year, but additional work must include a comparison with observation data over a longer-term period. It is likely that the use of higher-resolution model PBLH estimates with a more frequent output interval (e.g., hourly) may be necessary; in this regard, data from a new operational regional model (with a horizontal resolution of $1.5 \mathrm{~km}$ ) being developed at KMA may play an important role toward better estimates of PBLH in the region. The revealed spatiotemporal characteristics of PBLH from the KWRF Model will be used as an important reference for future operational tuning and development of a new boundary layer scheme in the model. The constructed PBLH dataset can be applied to many related research including boundary layer $\mathrm{CO}_{2}$ dynamics and air pollutants dispersion.

\section{Appendix}

\section{EOF Analysis of Radiosonde Temperature Profiles}

Empirical orthogonal function (EOF) analysis, also known as principal component analysis (PCA), can illuminate the patterns that explain the most variability within a dataset. In this paper, EOF analysis is applied to 06UTC (15LST) Osan radiosonde temperature profiles. The data was first divided by season: June to August 2010 (summer), September to November 2010 (autumn), December 2010 to February 2011 (winter), and March to May 2011 (spring). For EOF analysis, data must be on a common vertical grid. Thus, the data were interpolated linearly to every 100 feet from 100 to 4000 feet, and records with missing data were ignored. Next, the mean profile was subtracted from the dataset so that the EOFs explain variability about the mean. Then, EOF analysis was performed separately on each variable for each season by computing the covariance matrix in space and its eigenvalue decomposition, and ordering the eigenvalues and eigenvectors by explained variance. For brevity, only temperature results are reported here. EOF pattern vectors can be rotated to relax the orthogonality constraint, which aids the physical interpretation of results [46, 47]. Without rotation, the orthogonality constraint of EOFs leads to the emergence of Buell patterns, which are characteristic of 
domain shape and can appear regardless of the field under consideration [46]; here we use the varimax technique. It should also be noted that the sign of the pattern vector is irrelevant for physical interpretation, only the shape.

\section{Conflict of Interests}

The authors declare that there is no conflict of interests regarding the publication of this paper.

\section{Acknowledgments}

This study was supported by the Korea Meteorological Administration Research and Development Program under Grant CATER 2013-3030. The HFK data were provided by KoFlux from the projects funded by Korea Meteorological Administration and the A3 program of National Research Foundation of Korea. The first author thanks Juyeol Yun and Aastha (Bindu Malla Thakuri) for their valuable KoFlux site management.

\section{References}

[1] R. B. Stull, An Introduction to Boundary Layer Meteorology, Kluwer Academic Publishers, Norwell, Mass, USA, 1988.

[2] S.-Y. Hong and H.-L. Pan, "Nonlocal boundary layer vertical diffusion in a medium-range forecast model," Monthly Weather Review, vol. 124, no. 10, pp. 2322-2339, 1996.

[3] S.-H. Shin and K.-J. Ha, "Effects of spatial and temporal variations in PBL depth on a GCM," Journal of Climate, vol. 20, no. 18, pp. 4717-4732, 2007.

[4] H. Nagai, H. Terada, and M. Chino, "Relation between nasty smell at Kanto area on 28 Aug 2000 and eruption at Miyake Island: examination by numerical simulation," Tenki, vol. 48, pp. 227-230, 2001 (Japanese).

[5] D. J. Jacob, Introduction to Atmospheric Chemistry, Princeton University Press, 1999.

[6] R. Latha and B. S. Murthy, "Boundary layer signatures of consecutive thunderstorms as observed by Doppler sodar over western India," Atmospheric Research, vol. 99, no. 2, pp. 230240, 2011.

[7] M. R. Raupach, O. T. Denmead, and F. X. Dunin, "Challenges in linking atmospheric $\mathrm{CO}_{2}$ concentrations to fluxes at local and regional scales," Australian Journal of Botany, vol. 40, no. 4-5, pp. 697-716, 1992.

[8] O. T. Denmead, M. R. Raupach, F. X. Dunin, H. A. Cleugh, and R. Leuning, "Boundary layer budgets for regional estimates of scalar fluxes," Global Change Biology, vol. 2, no. 3, pp. 255-264, 1996.

[9] G. C. Holzworth, "Estimates of mean maximum mixing depths in the contiguous United States," Monthly Weather Review, vol. 92, pp. 235-242, 1963.

[10] J. L. Heffter, “Transport layer depth calculations," in Proceedings of the 2nd Joint Conference on Applications of Air Pollution Meteorology, New Orleans, La, USA, 1980.

[11] W. M. Angevine, A. B. White, and S. K. Avery, "Boundary-layer depth and entrainment zone characterization with a boundarylayer profiler," Boundary-Layer Meteorology, vol. 68, no. 4, pp. 375-385, 1994.
[12] P. Seibert, F. Beyrich, S.-E. Gryning, S. Joffre, A. Rasmussen, and P. Tercier, "Review and intercomparison of operational methods for the determination of the mixing height," Atmospheric Environment, vol. 34, no. 7, pp. 1001-1027, 2000.

[13] S. Liu and X. Z. Liang, "Observed diurnal cycle climatology of planetary boundary layer height," Journal of Climate, vol. 23, no. 21, pp. 5790-5809, 2010.

[14] M. Haeffelin, F. Angelini, Y. Morille et al., "Evaluation of mixing-height retrievals from automatic profiling lidars and ceilometers in view of future integrated networks in Europe," Boundary-Layer Meteorology, vol. 143, no. 1, pp. 49-75, 2012.

[15] S.-U. Park and I.-H. Yoon, "Estimation of atmospheric boundary layer parameters using routinely available meteorological data," Journal of the Korean Meteorological Society, vol. 27, pp. 32-54, 1991.

[16] J.-B. Lee, "A study on the air pollution potential in the central part of Korea," Journal of Korea Air Pollution Research Association, vol. 7, pp. 41-47, 1991 (Korean).

[17] Y.-G. Kim, "Calculation of the convective mixed layer by estimation of sensible heat flux," Journal of the Korean Environmental Sciences Society, vol. 7, pp. 639-645, 1998 (Korean).

[18] J.-S. Choi and S.-O. Baek, "An approach to estimate daily maximum mixing height (DMMH) in Pohang, Osan, and Kwangju areas-analysis of 10 years data from 1983 to 1992," Journal of Korea Air Pollution Research Association, vol. 14, pp. 379-385, 1998 (Korean).

[19] S.-J. Lee, J. Kim, and C.-H. Cho, "An automated monitoring of atmospheric mixing height from routine radiosonde profiles over South Korea using a web-based data transfer method," Environmental Monitoring and Assessment. In press.

[20] S.-C. Yoon, J.-G. Won, S.-W. Kim, and G.-M. Lim, "Measurement of mixed layer height using Lidar," in Proceedings of Korean Society for Atmospheric Environment, pp. 436-437, 1999.

[21] S.-J. Lee and H. Kawai, "Mixing depth estimation from operational JMA and KMA wind-profiler data and its preliminary applications: examples from four selected sites," Journal of the Meteorological Society of Japan, vol. 89, no. 1, pp. 15-28, 2011.

[22] K.-D. Min, S.-H. Kim, K.-E. Kim, and B.-H. Kwon, "Seasonal and local characteristics of atmospheric mixed layer over Kyungpook Province," Journal of Korean Meteorological Society, vol. 35, pp. 539-548, 1999.

[23] E. H. Berbery and E. A. Collini, "Springtime precipitation and water vapor flux over southeastern South America," Monthly Weather Review, vol. 128, no. 5, pp. 1328-1346, 2000.

[24] W. C. Skamarock, J. B. Klemp, J. Dudhia et al., "A Description of the Advanced Research WRF Version 3," NCAR Technical Note NCAR/TN-475+STR, National Center for Atmospheric Research, Boulder, Colo, USA, 2008, http://www.mmm.ucar .edu/wrf/users/docs/arw_v3.pdf.

[25] I.-H. Cho, H.-D. Yoo, and J.-O. Lim, "Implementation and test run of the next generation regional forecast model (KWRF)," in Proceedings of Korean Meteorological Society, pp. 368-369, 2005 (Korean).

[26] J. Dudhia, "Numerical study of convection observed during the winter monsoon experiment using a mesoscale twodimensional model," Journal of the Atmospheric Sciences, vol. 46, no. 20, pp. 3077-3107, 1989.

[27] E. J. Mlawer, S. J. Taubman, P. D. Brown, M. J. Iacono, and S. A. Clough, "Radiative transfer for inhomogeneous atmospheres: RRTM, a validated correlated-k model for the longwave," Journal of Geophysical Research D, vol. 102, no. 14, pp. 1666316682, 1997. 
[28] S.-Y. Hong and J.-O. Lim, "The WRF single-moment 6-class microphysics scheme (WSM6)," Journal of the Korean Meteorological Society, vol. 42, pp. 129-151, 2006.

[29] J. S. Kain and J. Kain, "The Kain-Fritsch convective parameterization: an update," Journal of Applied Meteorology, vol. 43, no. 1, pp. 170-181, 2004.

[30] S.-Y. Hong, Y. Noh, and J. Dudhia, "A new vertical diffusion package with an explicit treatment of entrainment processes," Monthly Weather Review, vol. 134, no. 9, pp. 2318-2341, 2006.

[31] A. S. Monin and A. M. Obukhov, "Osnovnye zakonomernosti turbulentnogo peremeshivanija v prizemnom sloe atmosfery," Trudy Geofizicheskogo Instituta, Akademiya Nauk SSSR, vol. 24, no. 151, pp. 163-187, 1954.

[32] Z.I. Janjić, “The surface layer in the NCEP eta model," in Proceedings of the 11th Conference on Numerical Weather Prediction, Norfolk, Va, USA, August 1996.

[33] Z.I. Janjić, "Nonsingular implementation of the Mellor-Yamada level 2.5 scheme in the NCEP Meso model," NCEP Office Note 437, 2002.

[34] F. Chen and J. Dudhia, "Coupling and advanced land surfacehydrology model with the Penn State-NCAR MM5 modeling system-part I: model implementation and sensitivity," Monthly Weather Review, vol. 129, no. 4, pp. 569-585, 2001.

[35] D.-K. Lee, D.-Y. Eom, J.-W. Kim, and J.-B. Lee, "High-resolution summer rainfall prediction in the JHWC real-time WRF system," Asia-Pacific Journal of Atmospheric Sciences, vol. 46, no. 3, pp. 341-353, 2010.

[36] H.-Y. Choi, J.-H. Ha, D.-K. Lee, and Y.-H. Kuo, "Analysis and simulation of mesoscale convective systems accompanying heavy rainfall: the goyang case," Asia-Pacific Journal of Atmospheric Sciences, vol. 47, no. 3, pp. 265-279, 2011.

[37] S.-H. Jung, E.-S. Im, and S.-O. Han, “The effect of topography and sea surface temperature on heavy snowfall in the Yeongdong region: a case study with high resolution WRF simulation," Asia-Pacific Journal of Atmospheric Sciences, vol. 48, pp. 259273, 2012.

[38] S.-J. Lee, D. F. Parrish, S.-Y. Park et al., "Effects of 2-m air temperature assimilation and a new near-surface observation operator on the NCEP gridpoint statistical-interpolation system," Asia-Pacific Journal of Atmospheric Sciences, vol. 47, no. 4, pp. 353-376, 2011.

[39] G. Svensson, A. A. M. Holtslag, V. Kumar et al., "Evaluation of the diurnal cycle in the atmospheric boundary layer over land as represented by a variety of single-column models: the second GABLS experiment," Boundary-Layer Meteorology, vol. 140, no. 2, pp. 177-206, 2011.

[40] H. H. Shin and S.-Y. Hong, "Intercomparison of planetary boundary-layer parametrizations in the WRF model for a single day from CASES-99," Boundary-Layer Meteorology, vol. 139, no. 2, pp. 261-281, 2011.

[41] S. Berman, J.-Y. Ku, and S. T. Rao, "Spatial and temporal variation in the mixing depth over the Northeastern United States during the summer of 1995," Journal of Applied Meteorology, vol. 38, no. 12, pp. 1661-1673, 1999.

[42] Y.-H. Kim and J.-J. Baik, "Maximum urban heat island intensity in Seoul," Journal of Applied Meteorology, vol. 41, pp. 651-659, 2002.

[43] S.-H. Lee and H.-D. Kim, "Effects of regional warming due to urbanization on daytime local circulations in a complex basin of the Daegu metropolitan area, Korea," Journal of Applied Meteorology and Climatology, vol. 47, no. 5, pp. 1427-1441, 2008.
[44] J.-H. Kim and I.-U. Chung, "Study on mechanisms and orographic effect for the springtime downslope windstorm over the Yeongdong region," Atmosphere, vol. 16, pp. 67-83, 2006 (Korean).

[45] S.-J. Lee and Y.-C. Kim, "A numerical forecast and verification of the aircraft turbulence observed over South Korea," AsiaPacific Journal of Atmospheric Sciences, vol. 38, pp. 493-507, 2002 (Korean).

[46] M. B. Richman, "Rotation of principal components," Journal of Climatology, vol. 6, no. 3, pp. 293-335, 1986.

[47] S. J. Greybush, S. E. Haupt, and G. S. Young, "The regime dependence of optimally weighted ensemble model consensus forecasts of surface temperature," Weather and Forecasting, vol. 23, no. 6, pp. 1146-1161, 2008. 

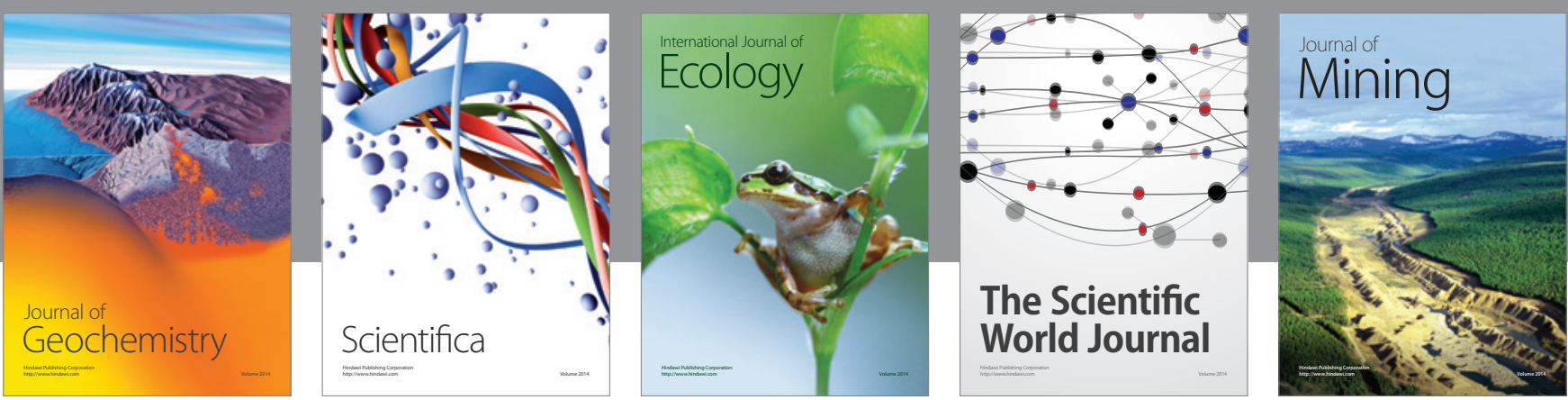

The Scientific World Journal
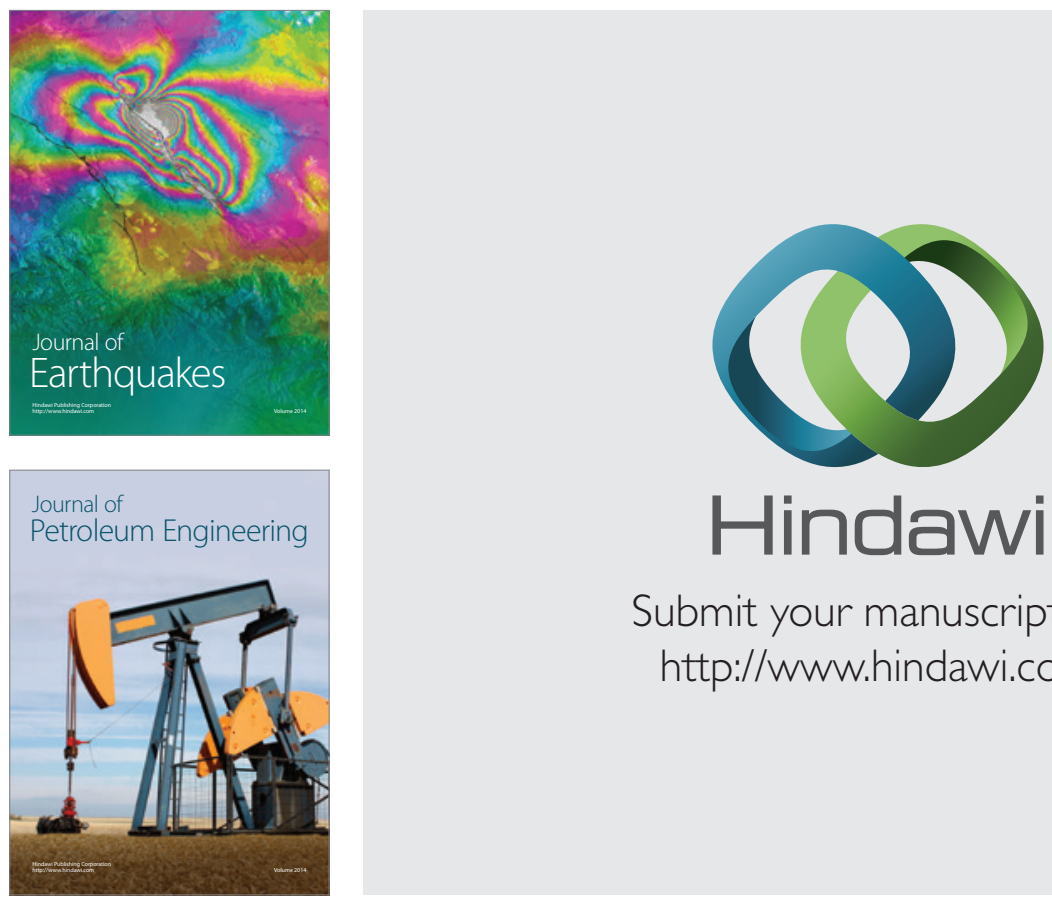

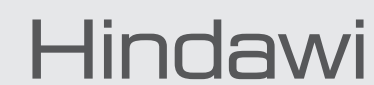

Submit your manuscripts at

http://www.hindawi.com
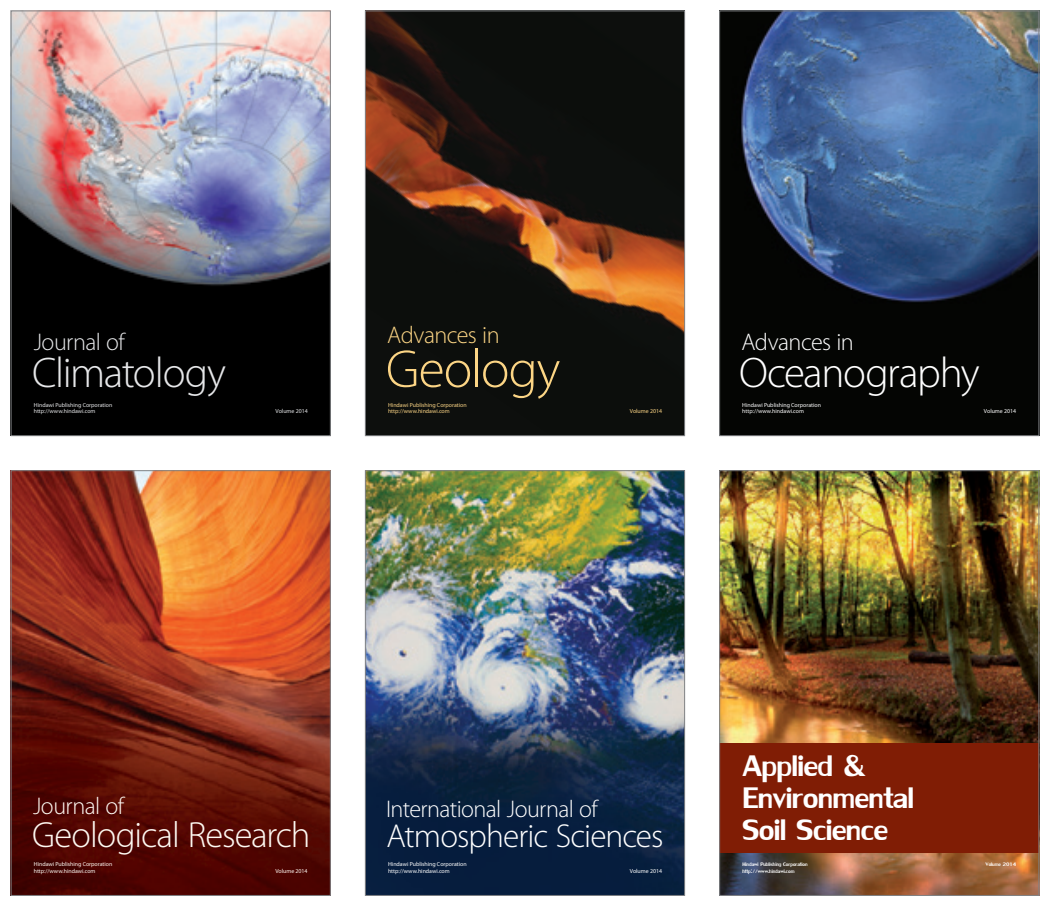
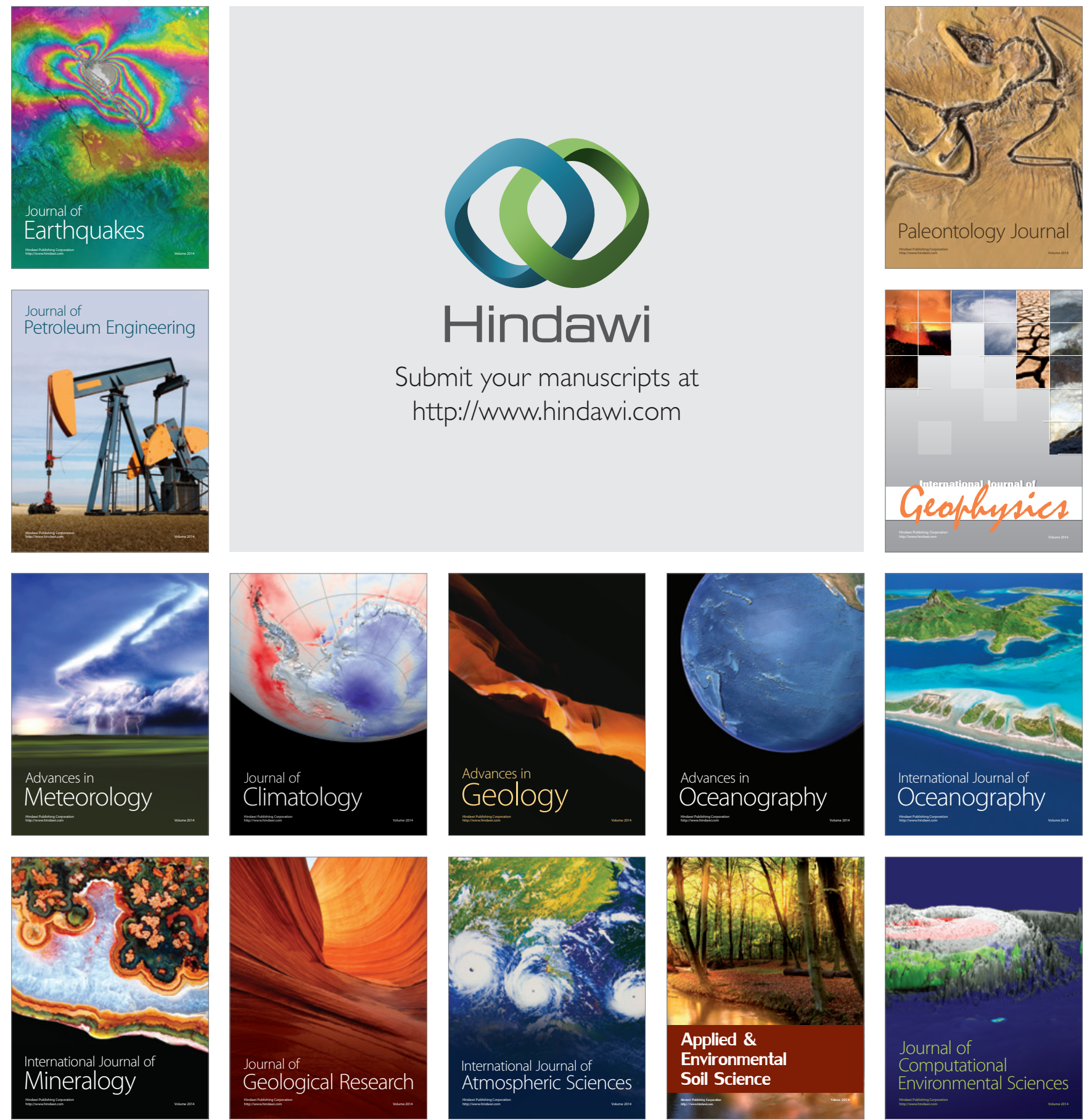